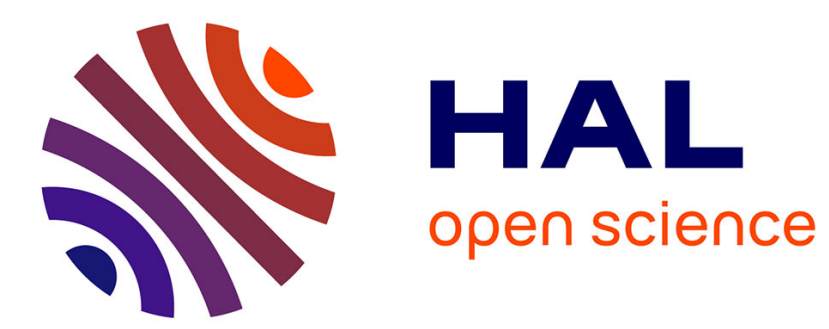

\title{
HÔTEL ET GOUVERNEMENT SOUS LES DERNIERS CAPÉTIENS DIRECTS
}

Olivier Canteaut

\section{To cite this version:}

Olivier Canteaut. HÔTEL ET GOUVERNEMENT SOUS LES DERNIERS CAPÉTIENS DIRECTS.

Bibliotheque- Ecole des Chartes, A paraître, 168, pp.373-410. halshs-01663489

\section{HAL Id: halshs-01663489 \\ https://shs.hal.science/halshs-01663489}

Submitted on 18 Dec 2017

HAL is a multi-disciplinary open access archive for the deposit and dissemination of scientific research documents, whether they are published or not. The documents may come from teaching and research institutions in France or abroad, or from public or private research centers.
L'archive ouverte pluridisciplinaire HAL, est destinée au dépôt et à la diffusion de documents scientifiques de niveau recherche, publiés ou non, émanant des établissements d'enseignement et de recherche français ou étrangers, des laboratoires publics ou privés. 


\title{
HÔTEL ET GOUVERNEMENT SOUS LES DERNIERS CAPÉTIENS DIRECTS
}

\author{
par
}

\author{
OLIVIER CANTEAUT
}

Ni Adam Héron, ni Robillard de Gamaches, ni le Borgne de Séry n'ont laissé de trace marquante dans l'histoire, et ce depuis les chroniques médiévales ${ }^{1}$. Tous trois, chambellans du roi de France Philippe V en

Les abréviations suivantes seront employées. AN : Archives nationales ; - BNF : Bibliothèque nationale de France;-Boutaric : Actes du parlement de Paris. Ire série, de l'an 1254 à l'an 1328, par Edgard Boutaric, Paris, 1863-1867, 2 vol. (Archives de l'Empire, Inventaires et documents);-Charles IV JT : Les journaux du Trésor de Charles IVle Bel, éd. Jules Viard, Paris, 1917 (Collection de documents inédits sur l'histoire de France) ; - Charles IV RTC: Registres du Trésor des chartes : inventaire analytique, t. II : Règnes des fils de Philippe le Bel, $2^{\mathrm{e}}$ partie : Règne de Charles IV le Bel, par Jean Guerout, Henri Jassemin et Aline Vallée, Paris, 1999 (Archives nationales, Inventaires et documents); - Louis X RTC : Registres du Trésor des chartes : inventaire analytique, t. II : Règnes des fils de Philippe le Bel, $1^{\text {re }}$ partie : Règnes de Louis X le Hutin et de Philippe V le Long, par J. Guerout, dir. Robert Fawtier, Paris, 1966 (Archives nationales, Inventaires et documents) ;-Philippe IV JT : Les journaux du Trésor de Philippe IVle Bel, éd. J. Viard, Paris, 1940 (Collection de documents inédits sur l'histoire de France); - Philippe IV RTC : Registres du Trésor des chartes : inventaire analytique, t. I : Règne de Philippe le Bel, par Jean Glénisson et J. Guerout, dir. R. Fawtier, Paris, 1958 (Archives nationales, Inventaires et documents);-Philippe V RTC : Registres du Trésor des chartes : inventaire analytique, $\mathrm{t}$. II : Règnes des fils de Philippe le Bel, $1^{\mathrm{re}}$ partie : Règnes de Louis X le Hutin et de Philippe Vle Long, par J. Guerout, dir. R. Fawtier, Paris, 1966 (Archives nationales, Inventaires et documents);-Philippe VI JT : Les journaux du Trésor de Philippe VI de Valois, suivis de l' «Ordinarium thesauri» de 1338-1339, éd. J. Viard, Paris, 1899 (Collection de documents inédits sur l'histoire de France); - Philippe VI RTC : Registres du Trésor des chartes : inventaire analytique, $\mathrm{t}$. III : Règne de Philippe de Valois, par A. Vallée et J. Viard, Paris, 1978-1984, 3 vol. (Archives nationales, Inventaires et documents).

1. À l'exception d'une brève allusion au Borgne de Séry dans les Grandes chroniques de France en 1328 (voir note 18), aucun d'entre eux n'est cité dans les principales chroniques du début du XIve siècle, que ce soit dans la continuation de la chronique de Guillaume de Nangis, dans celle de Jean de Saint-Victor, dans la chronique parisienne anonyme, ou encore dans les Grandes chroniques de France (Chronique latine de Guillaume de Nangis de 1113 à 1300 avec les continuations de cette chronique de 1300 à 1368, éd. Hercule Géraud, Paris,

Olivier Canteaut, maître de conférences à l'École nationale des chartes, 19 rue de la Sorbonne, 75005 Paris. <olivier.canteaut@enc.sorbonne.fr> 
$1316^{2}$, sont pourtant les successeurs du favori de Philippe III Pierre de La Broce $^{3}$, ou encore d'Enguerran de Marigny, pendu à peine un an avant leur nomination ${ }^{4}$. Or si ces chambellans partagent une même origine sociale ${ }^{5}$, Pierre de La Broce et Marigny se distinguent de leurs successeurs en exercice sous Philippe V par une tout autre fortune politique : tous deux ont manifestement su concrétiser le potentiel politique que recèle la fonction de chambellan du roi, qui permet d'être quotidiennement en contact avec le souverain, et ils attestent la place que peuvent occuper les officiers domestiques de l'Hôtel dans le gouvernement capétien.

Ainsi, aux $\mathrm{XI}^{\mathrm{e}}$ et $\mathrm{XII}^{\mathrm{e}}$ siècles, les grands officiers de la Couronne ont pu exercer une forte influence sur le roi ${ }^{6}$; mais ils ont vu leur pouvoir décroître à la fin du XII ${ }^{\mathrm{e}}$ siècle, sous l'effet des politiques de Louis VII et de

1843 [Société de l'histoire de France]; Jean de Saint-Victor, « Excerpta e Memoriale historiarum... », dans Recueil des historiens des Gaules et de la France, t. XXI, éd. Joseph-Daniel Guigniaut et Natalis de Wailly, Paris, 1855, p. 630-689; «Chronique parisienne anonyme de 1316 à 1339, précédée d'additions à la chronique française dite de Guillaume de Nangis (1206-1316) », éd. Amédée Hellot, dans Mémoires de la Société de l'histoire de Paris et de l'île-de-France, t. 11, 1884, p. 1-207; Les grandes chroniques de France, éd. J. Viard, Paris, 1920-1953, t. VIII à X [Société de l'histoire de France]).

2. Voir, en annexe, la liste des chambellans de 1285 à 1328.

3. Sur Pierre de La Broce, chambellan de 1266 à 1278, voir Charles-Victor Langlois, Le règne de Philippe III le Hardi, Paris, 1887, p. 13-32, et William Chester Jordan, « The struggle for influence at the court of Philip III : Pierre de La Broce and the French aristocracy », dans French historical studies, t. 24, 2001, p. 439-468.

4. Sur la chute de Marigny, voir Jean Favier, Un conseiller de Philippe le Bel : Enguerran de Marigny, Paris, 1963 (Mémoires et documents publiés par la Société de l'École des chartes, 16), p. 191-220 ; rééd. dans id., Un roi de marbre : Philippe le Bel, Enguerran de Marigny, Paris, 2005, p. 509-829 et 851-865, aux p. 705-733 (les références suivantes indiqueront successivement les pages des deux éditions).

5. Tous sont issus de la petite noblesse. Sur les origines sociales de Marigny et de ses collègues sous Philippe IV, voir note 66 ; sur celles de Pierre de La Broce, voir W. C. Jordan, «The struggle...», p. 441, et Xavier Hélary, «Pierre de La Broce, seigneur féodal, et le service militaire sous Philippe III : l'ost de Sauveterre (1276) », dans Journal des savants, 2006, p. 275-305, aux p. 286 et $288-289$, n. 55. Quant aux trois chambellans de Philippe V, ils appartiennent à des familles dont les origines sont très mal connues - la généalogie de la famille de Gamaches telle qu'elle est reconstituée par le père Anselme commence par exemple au milieu du xiv siècle (le P. Anselme de Sainte-Marie, Histoire généalogique et chronologique de la maison royale de France, des pairs, des grands officiers de la Couronne et de la maison du roy et des anciens barons du royaume..., continuée par Honoré

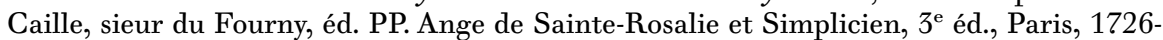
1733, 9 vol., t. VIII, p. 690-691) - et ils détiennent tous trois des seigneuries et fiefs d'importance modeste: Robillard de Gamaches à Bonnemare (Eure, cant. Étrépagny, comm. Gamaches; Philippe V RTC, n⿳0 3591), Gui de Séry à Séry (Indre, cant. Neuvy-SaintSépulchre, comm. Cluis; Philippe VI RTC, $\mathrm{n}^{\circ}$ 3775) et Adam Héron à Corbeil (Philippe V RTC, $\mathrm{n}^{\circ}$ 2046).

6. Jean-François Lemarignier, Le gouvernement royal aux premiers temps capétiens (9871108), Paris, 1965, p. 148-157; Éric Bournazel, Le gouvernement capétien au XII siècle (1108-1180): structures sociales et mutations institutionnelles, Limoges, 1975, p. 15-16, 94-99 et 112-115. 
Philippe Auguste ${ }^{7}$. À la Chambre, la réalité de la charge domestique et l'influence politique du chambrier de France ont été endossées par des officiers subalternes ${ }^{8}$ : le chambellan de France ${ }^{9}$ et les chambellans du roi, en nombre variable ${ }^{10}$, qui se substituent en quelque sorte au cham-

7. Ibid., p. 22-23 et surtout p. 115-127.

8. Ibid., p. 121-122. Le dernier chambrier à avoir joué un rôle politique notable est Jean de Beaumont, dans les années 1240 ; son influence s'exerçait cependant bien plus dans les affaires militaires qu'à la Chambre (Quentin Griffiths, « New men among the lay counsellors of saint Louis' Parlement », dans Medieval studies, t. 32, 1970, p. 234-272, à la p. 235).

9. Cet office apparaît sans doute au milieu du XIII ${ }^{\mathrm{e}}$ siècle : la première mention d'un chambellan de France concerne Pierre de Villebéon et date de 1258 (Q. Griffiths, « New men... », p. 235) et d'autres officiers de l'Hôtel se voient à la même époque pourvus du qualificatif « de France », comme le «panetier de France » attesté à compter de 1249 (ibid., p. 237). Ces hommes acquièrent ainsi un rang proche de celui des grands officiers de la Couronne apparus depuis le $\mathrm{xI}^{\mathrm{e}}$ siècle. Toutefois, jusqu'au début du $\mathrm{XIV}^{\mathrm{e}}$ siècle, bien des textes n'opèrent pas une distinction claire entre ces grands officiers « de France » et leurs homologues plus modestes, qualifiés d'officiers « du roi » : dans les registres de la chancellerie, Mathieu de Trie est ainsi qualifié alternativement de « chambellan de France » (Philippe IV RTC, $\mathrm{n}^{\text {os }} 280$ et 1944; Louis X RTC, $\mathrm{n}^{\text {os }} 97$ et 159) et de « chambellan » (Philippe IV RTC, $\mathrm{n}^{\text {os }} 315,413,467$ et 690 ; Louis X RTC, $\mathrm{n}^{\circ} 16$ ). Par la suite, nombre d'historiens modernes mêlent chambellans de France et chambellans du roi dans les listes d'officiers qu'ils ont pu établir (Jean du Tillet, Recueil des roys de France, leurs couronne et maison, ensemble le rengs [sic] des grands de France, Paris, 1580, p. 302-303; le P. Anselme, Histoire généalogique..., t. VIII, p. 437-459). Pourtant, les chambellans de France se distinguent des simples chambellans par un statut et un recrutement social sensiblement plus élevés, similaires à ceux des grands officiers de la Couronne (O. Canteaut, Gouvernement et hommes de gouvernement sous les derniers Capétiens, 1313-1328, thèse de doctorat, histoire, Univ. Paris-I, 2005, 3 vol., multigr., t. II, p. 398, n. 1766). En témoigne, sous Philippe IV, la nomination comme chambellan de France de Mathieu IV de Montmorency, dont la famille a déjà fourni à la royauté plusieurs grands officiers (Brigitte Bedos, La châtellenie de Montmorency des origines à 1368 : aspects féodaux, sociaux et économiques, Pontoise, 1980, p. 97). Toutefois, l'écart social qui existait originellement entre chambellans de France et chambellans du roi, et qui se traduisait par l'absence de liens familiaux entre les deux groupes (voir note 98), s'estompe sous Philippe VI. On voit alors un Montmorency, Charles, devenir chambellan du roi en 1350 (Philippe VI RTC, $\mathrm{n}^{\circ}$ 7159), ou encore un parent du chambellan de France Mathieu de Trie, lui aussi prénommé Mathieu, nommé chambellan du roi en 1346 (Philippe VI RTC, $n^{\circ}$ 6481). Dans le même temps, les chambellans de France et leurs familles, tels les Melun, nouent quelques alliances lointaines avec d'anciens chambellans du roi : le fils du chambellan de France Jean de Melun épouse par exemple avant 1341 Jeanne Crespin (Philippe VI RTC, $\mathrm{n}^{\circ}$ 4325), elle-même nièce de l'épouse de Jean de Bouville, ancien chambellan de Philippe IV (Émile Richemond, Recherches généalogiques sur la famille des seigneurs de Nemours $d u X I I^{e}$ au $X V^{e}$ siècle, Fontainebleau, 1907-1908, 2 vol., t. II, planche entre les p. 96 et 97) et son petit-fils, lui aussi prénommé Jean, épouse en 1350 Ide de Marigny, petite-fille d'Enguerran (BNF, P. O. 1853, dossier 42781, Marigny, $\mathrm{n}^{\circ}$ 2).

10. Le nombre de chambellans n'est pas fixe : il semble avoir oscillé entre trois à l'extrême fin du $\mathrm{XIII}^{\mathrm{e}}$ siècle ou durant le règne de Philippe $\mathrm{V}$, et treize sous Louis $\mathrm{X}$ (voir annexe). Cependant tous n'occupent pas la même position : apparemment, une place prééminente est toujours réservée à l'un d'entre eux, ainsi qu'en témoignent les gages plus élevés ou les privilèges qu'accordent à l'un des chambellans toutes les ordonnances de l'Hôtel (ordon- 
brier ${ }^{11}$. Pour autant, la monarchie française de la fin du XIII ${ }^{\mathrm{e}}$ siècle ou du début $d u \mathrm{XIV}^{\mathrm{e}}$ siècle n'est plus celle des premiers Capétiens. Entre-temps, les institutions spécialisées permettant au souverain de contrôler plus étroitement son royaume se sont multipliées et consolidées; elles acquièrent en outre une autonomie croissante vis-à-vis du souverain, qui n'y siège plus que rarement ${ }^{12}$. Pour reprendre les termes de Raymond Cazelles, se forge alors une «monarchie administrative » ${ }^{13}$, où service du roi et service de la Cou-

nance de Vincennes, 23 janvier 1286, art. 51-52, AN, JJ 57, fol. 4v; ordonnance du Bois de Vincennes, janvier 1291, art. 81-82, AN, JJ 57, fol. 15v; ordonnance de 1306-1307, art. 3, AN, JJ 57, fol. 49 - texte daté dans Ordonnances de l'Hôtel du roi, éd. Élisabeth Lalou, Orléans, 2006 [Aedilis, publications scientifiques, 5], en ligne, www.cn-telma.fr/ ordonnances/ordonnance 5 -; ordonnance du Bois de Vincennes, décembre 1316, art. 3, AN, JJ 57, fol. 57-v ; ordonnance de Lorris, 17 novembre 1317, art. 3, AN, JJ 57, fol. 74-v ; ordonnance de janvier 1322 , art. 3 , BNF, fr. 7855 , p. 265). Seuls trois de ces textes confèrent à cet homme un qualificatif spécifique : celui de «maistre chambellan » (AN, JJ 57, fol. 15v) - fréquemment attesté dès le début du XIII ${ }^{\mathrm{e}}$ siècle (Adolf Tobler et Erhard Lommatzsch, Altfranzösisches Wörterbuch, Berlin [puis] Wiesbaden, 1925-2002, 10 vol., t. II, col. 190) et employé au plus tard dans la seconde moitié de ce siècle par la monarchie capétienne (ibid. et Charles du Fresne, sieur du Cange, et al., Glossarium mediae et infimae latinitatis, éd. de Niort, 1883-1887, 10 vol., t. II, col. 40a) -, celui de « principal chambellan » (AN, JJ 57, fol. 49) et celui d' « ainsné » (BNF, fr. 7855, p. 265). Les titres de « premier chambellan » et de « grand chambellan » employés par l'historiographie - qui n'est pas sans les mêler avec le titre de « chambellan de France » - (voir par exemple J. du Tillet, Recueil..., p. 301-302, et Léon-Louis Borrelli de Serres, Recherches sur divers services publics du XIII e au XVII siècle, Paris, 1895-1909, 3 vol. ; réimpr. Genève, 1974, t. I, p. 277), ne sont en revanche pas attestés au début du XIv siècle; ils ne sont employés qu'à compter de la seconde moitié de ce siècle, en particulier par le duc d'Orléans (« premier grand chambellan d'Orlenois et de Valois », 1366, AN, J 158, Melun II, $\mathrm{n}^{\text {os }}$ 25-26; « premier chambellan », 1392, Louis-Claude Douët d'Arcq, Choix de pièces inédites relatives au règne de Charles VI, Paris, 1863-1864, 2 vol. [Société de l'histoire de France], t. I, p. 109, cité dans Dictionnaire du moyen français, www.atilf.fr/dmf). Ajoutons, à la suite de Jean Favier, que nombre d'auteurs ont considéré un peu vite que le chambellan le plus influent était nécessairement le principal chambellan (J. Favier, Un conseiller..., p. 74 / 585-586).

11. La similitude de leurs fonctions s'exprime, dès le milieu du $\mathrm{XII}^{\mathrm{e}}$ siècle, par l'emploi épisodique du terme camerarius, jusque-là réservé au chambrier, pour désigner les chambellans (É. Bournazel, Le gouvernement..., p. 121). Cette confusion terminologique persiste de lieu en lieu au xıII ${ }^{\mathrm{e}}$ siècle, en particulier pour le chambellan de France, même si elle va en se raréfiant (voir notes 54 et 174 ; voir également $\mathrm{AN}, \mathrm{J} 729, \mathrm{n}^{\circ} 157$, à propos de Pierre de La Broce, et une mention du $\mathrm{xv}^{\mathrm{e}}$ siècle, mais empruntée à un texte plus ancien, du chambellan de France Mathieu de Trie dans Obituaires de la province de Sens, dir. Auguste Longnon, t. I : Diocèses de Sens et de Paris, éd. Auguste Molinier, Paris, 1902 [Recueil des historiens de la France, Obituaires, 1], p. 637). Pour autant, les deux offices demeurent clairement distincts (voir É. Bournazel, Le gouvernement..., p. 121-122).

12. Voir l'exemple du Parlement étudié dans Jean Hilaire, «Le Roi et Nous : procédure et genèse de l'État aux XIII ${ }^{\mathrm{e}}$ et XIV ${ }^{\mathrm{e}}$ siècles », dans Histoire de la justice, t. 5, 1992, p. 3-18.

13. Raymond Cazelles, «Un problème d'évolution et d'intégration: les grands officiers de la Couronne de France dans l'administration nouvelle au Moyen Ấge », dans Annali della Fondazione italiana per la storia amministrativa, t. 1, 1964, p. 183-189, à la p. 184. 
ronne peuvent être disjoints ${ }^{14}$, et où la place des officiers de l'Hôtel au sein du gouvernement royal ne va plus de soi.

C'est dans ce contexte qu'il convient d'examiner la transformation, apparemment radicale, de la position des chambellans entre le règne de $\mathrm{Phi}$ lippe IV et celui de Philippe V. La chute de Marigny semble en effet témoigner de la fragilité politique croissante des chambellans, qui, en tant qu'officiers emblématiques de l'Hôtel, seraient les premières victimes d'une séparation accrue entre service de la Couronne et service de la personne royale.

La fonction première des chambellans est précisément de protéger le corps du roi. Cette charge se traduit par de multiples tâches domestiques. Les chambellans veillent ainsi à ce que nul ne pénètre indûment dans la chambre du roi et n'approche de son lit, comme le prescrit une ordonnance de $1318^{15}$. L'un d'entre eux a également l'obligation, peut-être dès le $\mathrm{xI}^{\mathrm{e}}$ siècle, de dormir la nuit au pied du lit du souverain ${ }^{16}$, et plusieurs ordonnances de Philippe V et de Charles IV rappellent ce devoir ${ }^{17}$. La tâche de protéger la personne royale leur incombe également sur le champ de bataille : les chambellans participent tous aux différentes campagnes militaires des derniers Capétiens et l'un d'eux, Hugues II de Bouville, meurt à Mons-en-Pévèle en défendant Philippe le Bel ${ }^{18}$. Cette protection du corps

14. Cette disjonction se dessine dès la fin du XII ${ }^{\mathrm{e}}$ siècle (É. Bournazel, Le gouvernement..., p. 127). Sur la notion de Couronne, voir notamment Raymond Cazelles, Société politique, noblesse et Couronne sous Jean le Bon et Charles V, Genève, 1982 (Mémoires et documents publiés par la Société de l'École des chartes, 28), p. 30 et 505.

15. Ordonnance de Bourges du 18 novembre 1318, art. 3, dans Ordonnances des roys de France de la troisième race recueillies par ordre chronologique..., éd. Eusèbe de Laurière et al., Paris, 1723-1849, 22 vol., t. I, p. 670.

16. É. Bournazel, Le gouvernement..., p. 99, n. 51. Selon Jean du Tillet, c'est cette obligation qui sous-tend à l'époque moderne le cérémonial des lits de justice et des états généraux, prévoyant que le chambellan de France soit couché aux pieds du souverain (J. du Tillet, Recueil des roys..., p. 300). Cet usage apparaît sous François I ${ }^{\text {er }}$, la tâche de siéger aux pieds du souverain étant alors indifféremment dévolue au grand chambellan de France ou au premier chambellan (Elizabeth A. R. Brown et Richard C. Famiglietti, The Lit de justice : semantics, ceremonial, and the Parlement of Paris, 1300-1600, Sigmaringen, 1994 [Beihefte der Francia, 31], p. 60, 64 et 67). Sur l'analyse de J. du Tillet, voir ibid., p. 21, n. 8.

17. AN, JJ 57, fol. 57v, art. 3 (décembre 1316); AN, JJ 57, fol. 74v, art. 3 (17 novembre 1317); BNF, fr. 7855 , p. 265-266, art. 3 (janvier 1322). Existait-il un tour de rôle pour exercer cette fonction ou revenait-elle à l'un des chambellans? J. Favier estime que les chambellans se partageaient sans doute cette tâche, mais sans qu'un tour de rôle régulier puisse être observé (Un conseiller..., p. 76-77 / 588).

18. Guillaume Guiart, «La branche des royaus lingnages », dans Recueil des historiens des Gaules et de la France, t. XXII, éd. N. de Wailly et Léopold Delisle, Paris, 1865, p. 171300, à la p. 298, v. 21284-21289. La présence de Pierre V de Chambly, ainsi que de trois futurs chambellans, Jean et Pierre II de Machau et Enguerran de Marigny, est aussi attestée lors de la bataille (ibid., p. 290, v. 20439, 20445 et 20446, édition corrigée dans J. Favier, Un conseiller..., p. 60 / 570). Signalons également que c'est au Borgne de Séry, sans doute l'un de 
du souverain peut aussi revêtir un tour plus symbolique, par exemple lorsqu'elle se prolonge au-delà de la mort du roi : Pierre de Villebéon, chambellan de Louis IX, est enterré à ses pieds à Saint-Denis ${ }^{19}$ et, depuis Louis IX, tous les souverains ont mis au nombre de leurs exécuteurs testamentaires un ou plusieurs de leurs chambellans ${ }^{20}$. Leur rôle est bien d'« assurer la sécurité du maître », ici-bas et dans l'au-delà ${ }^{21}$.

Par ailleurs le sceau royal, autre incarnation de la personne du souverain ${ }^{22}$, est confié à la garde des chambellans. Certes, ceux-ci ne prennent soin que du «petit sceau » du roi ${ }^{23}$, c'est-à-dire du sceau du secret, dont la charge symbolique n'est en rien comparable à celle du grand sceau que garde le chancelier ${ }^{24}$. Ils n'en sont pas moins, comme ce dernier, dépositai-

ses chambellans (voir note 236), que Philippe VI confia le soin de porter son heaume lors de la bataille de Cassel (Les grandes chroniques..., t. IX, p. 88, et Chronographia regum Francorum, éd. Henri Moranvillé, Paris, 1891-1897, 3 vol. [Société de l'histoire de France], t. II, p. 8).

19. Le P. Anselme, Histoire généalogique..., t. VIII, p. 439, et G. Guiart, « La branche des royaus lingnages »..., p. 209-210, v. 12042-12048 (cité dans É. Bournazel, Le gouvernement..., p. 100, n. 53, sous une référence erronée). Déjà, un chambellan de Louis VII était enterré aux pieds de celui-ci à l'abbaye de Barbeaux (ibid.).

20. Louis IX nomme en 1270 parmi ses exécuteurs testamentaires son chambellan Pierre de Villebéon (AN, J 403, $n^{\circ} 6$ ). La même année, Philippe III choisit lui aussi pour exécuteur testamentaire Pierre de Villebéon, auquel il adjoint Pierre de La Broce (AN, J 403, $\mathrm{n}^{\circ}$ 8), puis Jean Poucin et Pierre V de Chambly en 1284 (AN, J 403, $\mathrm{n}^{\circ} 11$ ). Philippe IV nomme à son tour des chambellans pour exécuteurs dans chacun de ses testaments: Hugues II de Bouville et Pierre V de Chambly en 1288 et 1293 (AN, J 403, n ${ }^{\text {os }} 12$ et 13); Enguerran de Marigny en 1311 (AN, J 403, no 17) ; le même Marigny, Pierre VII de Chambly et Hugues III de Bouville en 1314 (AN, J 403, no 18). Enfin, Louis X met en 1316 Hugues d'Augeron au nombre de ses exécuteurs testamentaires (AN, J 404 $\left.{ }^{\mathrm{A}}, \mathrm{n}^{\mathrm{o}} 22\right)$. L'ensemble des testaments royaux capétiens fait actuellement l'objet d'une édition collective dans le cadre du projet « Derniers Capétiens » dirigé par Xavier Hélary.

21. É. Bournazel, Le gouvernement..., p. 99-100.

22. Sur les rapports qu'entretiennent le sigillant et son sceau, voir Brigitte Bedos-Rezak, «Une image ontologique : sceau et ressemblance en France préscolastique (1000-1200) », dans Études d'histoire de l'art offertes à Jacques Thirion, des premiers temps chrétiens au $X X^{e}$ siècle, éd. Alain Erlande-Brandenburg et Jean-Michel Leniaud, Paris, 2001 (Matériaux pour l'histoire publiés par l'École des chartes, 3), p. 39-50, à la p. 49.

23. Ordonnance de Saint-Germain de juillet 1316, art. 10, AN, JJ 57, fol. 42. La garde du petit sceau était-elle dévolue à un seul des chambellans ? C'est ce que peut donner à penser la remise au principal chambellan, Adam Héron, d'une bourse de velours et d'une chaîne d'argent pour conserver ce sceau en 1316 (Comptes de l'argenterie des rois de France au $X I V^{e}$ siècle, éd. L.-C. Douët d'Arcq, Paris, 1851 [Société de l'histoire de France], p. 14-15). Paul Lehugeur, trompé par une copie de l'ordonnance de Saint-Germain-en-Laye de juillet 1316, prétend que cette tâche était confiée par Philippe $\mathrm{V}$ à deux de ses chambellans (Paul Lehugeur, Histoire de Philippe Vle Long, roi de France, 1316-1322, t. II : Le mécanisme du gouvernement, Paris, 1931 ; réimpr. Genève, 1975, p. 92). Quant à Jean du Tillet, il affirme que cette fonction incombe au chambellan de France ou, en son absence, au plus ancien chambellan (J. du Tillet, Recueil des roys..., p. 300).

24. Sur la place du grand sceau dans ce «théâtre du pouvoir » qu'est l'acte royal, voir Olivier Guyotjeannin, «Écrire en chancellerie », dans «Auctor et auctoritas » : invention et 
res de l'un des symboles de l'autorité royale. En tant que tels, ils constituent également un rouage notable de l'administration royale, même si nous ignorons en large part les procédures qui président à l'usage de ce sceau ${ }^{25}$, ainsi que la chronologie qui a abouti à l'émergence de ce rôle des chambellans ${ }^{26}$. Toujours est-il que ceux-ci doivent sceller de ce sceau la correspondance du souverain, en particulier avec les princes étrangers, ainsi que, de plus en plus fréquemment, les actes émis au nom du roi lorsque le chancelier est absent de la cour ${ }^{27}$. Une ordonnance de 1318 leur confie en outre le

conformisme dans l'écriture médiévale, Paris, 2001 (Mémoires et documents de l'École des chartes, 59), p. 17-35, aux p. 18-19. Rappelons également qu'à compter du milieu du $\mathrm{Xv}^{\mathrm{e}}$ siècle, le grand sceau est exhibé lors des entrées royales (Bernard Guenée et Françoise Lehoux, Les entrées royales françaises de 1328 à 1515, Paris, 1968 [Sources d'histoire médiévale, 5], p. 25).

25. Aucun document de la pratique n'éclaire les procédures qui président au scellage des actes à l'aide du petit sceau. Il n'existe par exemple aucune trace d'un personnel subalterne, en particulier d'un chauffe-cire, à même d'assister les chambellans lors du scellage. De plus, aucun notaire n'est spécifiquement attaché à la rédaction des actes scellés par les chambellans - sans pour autant qu'il faille considérer, avec Paul Lehugeur, que les chambellans sont chargés eux-mêmes de rédiger des lettres (P. Lehugeur, Histoire de Philippe V..., t. II, p. 9091) : cette affirmation se fonde sur une interprétation erronée de l'article 10 de l'ordonnance de Saint-Germain-en-Laye (AN, JJ 57, fol. 42), qui autorise les chambellans à «signer » certaines lettres, c'est-à-dire à les commander, ainsi que le confirme l'article 27 de l'ordonnance de Bourges (Ordonnances des roys de France..., t. I, p. 673). Au demeurant il n'est guère surprenant que les sources ne fassent pas mention d'un quelconque personnel subalterne aux côtés des chambellans, vu le nombre réduit d'actes scellés du sceau du secret. Aussi est-il tout à fait excessif de considérer, comme le fait Paul Lehugeur, qu'au début du XIV siècle, le chambellan qui porte le sceau du secret est le « chef de la petite chancellerie, sorte de vice-chancelier, subcancellarius, de chancelier du secret et de la Chambre le roi » (P. Lehugeur, Histoire de Philippe V..., t. II, p. 94). Il faut attendre les années 1330 - ou, au mieux, le milieu des années 1320 - pour assister à l'émergence, du reste avortée, d'une chancellerie du secret; encore ignorons-nous le rôle qu'y jouent les chambellans (voir notes 168 et 169).

26. La première attestation de ce rôle daterait de 1312 («Chronique de Guillaume Bardin », dans Jean-Joseph Vaissète et Claude de Vic, Histoire générale de Languedoc..., complétée par Auguste Molinier, Charles Robert, Paul Meyer et al., t. X, Toulouse, 1895, Preuves, col. 1-78, à la col. 30). Mais dès 1288 , nombre de lettres royaux qui, d'après leur mention hors teneur, ont été expédiées à l'initiative d'un chambellan, ont été scellées du sceau du secret plaqué en sus du grand sceau (AN, J 178, no 56 , et J 1020, n $^{\circ} 10$; AN, K 37 , $\mathrm{n}^{\text {os }} 8$ bis (a), 15 et 33; AN, L 1050, $\mathrm{n}^{\circ} 14$; AN, S 4076, $\mathrm{n}^{\circ} 27$; BNF, Clairambault 49, $\mathrm{n}^{\circ} 160$ ) ou du seul sceau du secret pendant (BNF, Clairambault $48, \mathrm{n}^{\circ} 27$, et Clairambault $\left.75, \mathrm{n}^{\circ} 170\right)$, signe des liens privilégiés qu'entretiennent dès cette date les chambellans avec le sceau du secret. Aussi Élisabeth Lalou considère-t-elle que, dès la fin du XIII ${ }^{\mathrm{e}}$ siècle, les chambellans portent le sceau du secret (É. Lalou, «Chancellerie et Hôtel à l'époque de Philippe le Bel », dans Écrit et pouvoir dans les chancelleries médiévales : espace français, espace anglais, actes du colloque international de Montréal, 7-9 septembre 1995, éd. Kouky Fianu et DeLloyd J. Guth, Louvain-la-Neuve, 1997 [FIDEM, Textes et études du Moyen Âge, 6], p. 13-24, à la p. 20).

27. Sur les usages du petit sceau, voir Robert-Henri Bautier, «Recherches sur la chancellerie royale au temps de Philippe VI », dans Bibliothèque de l'École des chartes, t. 122, 1964, p. 89-176, et t. 123, 1965, p. 313-459, au t. 122, p. 114-117 ; réimpr. dans id., Chartes, sceaux et chancelleries, t. II, Paris, 1990 (Mémoires et documents de l'École des chartes, 34), 
soin de sceller du sceau du secret les liasses de requêtes traitées par les maîtres des requêtes de l'Hôtel avant que celles-ci ne soient transmises à la chancellerie ${ }^{28}$, si bien que la majeure partie des requêtes soumises au roi doit transiter par leurs mains.

Il apparaît ainsi que les chambellans sont de véritables hommes de confiance pour le souverain; ils peuvent même se substituer occasionnellement à la personne royale, en particulier lors de la réception des hommages féodaux ${ }^{29}$. Cette confiance, ainsi que la fréquentation constante du roi qu'implique le service domestique des chambellans ${ }^{30}$, rejaillit inévitablement dans le champ du gouvernement du royaume.

L'activité des chambellans dépasse de ce fait très fréquemment les bornes domestiques de leur fonction. Ils sont en particulier chargés régulièrement par le souverain de missions importantes. Nombre d'entre elles touchent à la personne même du roi ou à sa famille. Philippe IV fait du chambellan de France Mathieu de Trie l'un de ses procureurs pour négocier en 1306 le mariage de son fils Robert ${ }^{31}$; Louis X envoie Hugues III de

p. 615-852, aux p. 640-643, et O. Canteaut, Philippe $V$ et son Conseil : le gouvernement royal de 1316 à 1322, thèse pour le dipl. d'archiviste paléographe, 2000, dactyl., t. I, p. 42, n. 89.

28. Ordonnance de Bourges du 16 novembre 1318, art. 4, dans Ordonnances des roys de France..., t. I, p. 670. Nous ignorons cependant si cette prescription a été appliquée.

29. Sur le rôle du chambellan de France lors des hommages, voir J. du Tillet, Recueil des roys..., p. 301; pour des exemples, voir J. Favier, Un conseiller..., p. 152-153 / 666 (1307) et $\mathrm{AN}, \mathrm{J} 634, \mathrm{n}^{\circ} 21$ (1329). Les chambellans touchent à cette occasion des droits versés par le vassal, comme le dispose une ordonnance de 1272 (Ordonnances des roys de France..., t. I, p. 296-297); des fragments de la comptabilité produite par ces droits nous sont parvenus dès 1256 au sein de la comptabilité générale de l'Hôtel (Les comptes sur tablettes de cire de Jean Sarrazin, chambellan de saint Louis, éd. É. Lalou, Turnhout, 2003 [Monumenta palaeographica Medii Aevi, Series gallica], p. 108-110, \$364-366), et sous Philippe IV, sous la forme d'un compte particulier « pour les feautés et les hommages » (Comptes royaux, 1285-1314, éd. R. Fawtier, collab. François Maillard, Paris, 1953-1956, 3 vol. [Recueil des historiens de la France, Documents financiers, 3], t. II, $\mathrm{n}^{\text {os }} 23844$ à 23891 ; sur la date de ce compte, voir note 191).

30. Toutes les ordonnances de l'Hôtel organisent le séjour des chambellans à la cour (voir par exemple les ordonnances de Vincennes du 23 janvier 1286, art. 51-53, et du Bois de Vincennes de janvier 1291, art. 81-82, AN, JJ 57, fol. 4v et 15v) et leur présence aux côtés du souverain est régulièrement attestée. Pierre VI de Chambly reçoit par exemple en 1301 des gages pour 380 jours passés à la cour (Les comptes sur tablettes de cire de la Chambre aux deniers de Philippe III le Hardi et Philippe IV le Bel, 1282-1309, éd. É. Lalou, dir. R.-H. Bautier, Paris, 1994 [Recueil des historiens de la France, Documents financiers, 8], p. 455, CO VIII, $\mathrm{n}^{\circ}$ 11); quant à Enguerran de Marigny, il ne s'absente de la cour que pour accomplir des missions diplomatiques (J. Favier, Un conseiller..., p. 82-83 / 593-594) et il est parmi les premiers aux côtés du roi sur son lit de mort (AN, J 390, n 10 , acte commandé par Marigny à Fontainebleau le 29 novembre 1314, et Charles Baudon de Mony, « La mort et les funérailles de Philippe le Bel d'après un compte rendu à la cour de Majorque », dans Bibliothèque de l'École des chartes, t. 58, 1897, p. 5-14, à la p. 12).

31. AN, J 408, $\mathrm{n}^{\circ} 12$. 
Bouville accueillir en Italie sa future seconde épouse, Clémence de Hongrie ${ }^{32}$; Philippe IV confie en 1314 à ce même Hugues et à Enguerran de Marigny, tous deux au nombre de ses exécuteurs testamentaires, le soin de veiller à la dot de sa belle-fille Blanche de Bourgogne 33 ; quant à Hugues II de Bouville, il a été chargé d'établir le compte des joyaux remis en dot à Marguerite, sœur de Philippe IV, lors de son mariage avec Édouard I ${ }^{\text {er }}$ d'Angleterre en $1299{ }^{34}$.

Comme en témoignent ces deux derniers exemples, les chambellans reçoivent également volontiers des commissions relatives aux finances. C'est qu'ils ont eu, durant tout le XIII ${ }^{\mathrm{e}}$ siècle, des compétences financières notables. L'un d'eux a été chargé de tenir les comptes de l'Hôtel jusqu'à l'apparition progressive, dans la seconde moitié du XIII ${ }^{\mathrm{e}}$ siècle, de la Chambre aux deniers, dotée d'un personnel spécialisé ${ }^{35}$; passé cette date, les chambellans s'occupent encore des comptes de la Chambre, et en particulier des joyaux, jusqu'à l'apparition d'un argentier au début du XIv ${ }^{\mathrm{e}}$ siècle ${ }^{36}$. Enfin - et c'est là une tâche qu'ils conserveront durablement - l'exercice de la direction de la Chambre les conduit à ordonnancer nombre de dépenses de l'Hôtel, en relation avec le clerc de la Chambre aux deniers ${ }^{37}$. Ils possèdent donc un indéniable savoir-faire comptable. C'est précisément sur celui-ci qu'est fondé le pouvoir de Marigny ${ }^{38}$, et sans doute celui de Pierre de La Broce avant lui ${ }^{39}$; quant à Hugues d'Augeron, chambellan de Louis $\mathrm{X}$, il cumule même son office avec celui de maître de la Chambre des comptes $^{40}$. Le roi confie de ce fait à ses chambellans diverses missions

32. Comptes du Trésor (1286, 1316, 1384, 1477), éd. R. Fawtier, dir. C.-V. Langlois, Paris, 1930 (Recueil des historiens de la France, Documents financiers, 2), n 1123.

33. AN, J 403, $\mathrm{n}^{\circ} 19$.

34. Comptes royaux, 1285-1314..., t. III, p. LXXIX-LXXx, $\mathrm{n}^{\circ} 98$, et Inventaire d'anciens comptes royaux dressé par Robert Mignon sous le règne de Philippe de Valois, éd. C.-V. Langlois, dir. L. Delisle, Paris, 1899 (Recueil des historiens de la France, Documents financiers, 1), $\mathrm{n}^{\circ} 1997$.

35. Les comptes [...] de Jean Sarrazin..., p. 19, et R.-H. Bautier, «Introduction », dans Les comptes [...] de la Chambre aux deniers..., p. xxv-xxxiv.

36. Dans les premières années du XIv siècle, c'est à Hugues II de Bouville que semble dévolue la garde des joyaux, ainsi qu'en témoignent plusieurs comptes (Inventaire d'anciens comptes..., $\mathrm{n}^{\circ} 2000$; voir également note 34). Sur l'apparition de l'argentier en 1316, voir note 105.

37. Voir par exemple Les comptes [...] de la Chambre aux derniers..., p. 778-781, CE I, $\mathrm{n}^{\text {os }} 168,187,199 \ldots$ Élisabeth Lalou signale également que des mandements royaux adressés aux trésoriers ont peut-être été munis du signet d'un des chambellans - même si les empreintes subsistantes s'avèrent bien tenues pour autoriser des comparaisons (É. Lalou, «Chancellerie et Hôtel... », p. 22, n. 36). Certains de ces mandements ont été expédiés sur ordre de la Chambre aux deniers (BNF, fr. 25697, $\mathrm{n}^{\text {os }} 22$ et 23).

38. Voir J. Favier, Un conseiller..., p. 98-108 / 609-619.

39. X. Hélary, « Pierre de La Broce... », p. 288-289.

40. Boutaric, n 4469; voir également O. Canteaut, Gouvernement..., t. III, p. 668, n. 3856. Après sa disgrâce, Pierre II de Machau sera quant à lui receveur en Gâtinais sous Philippe V (Philippe V RTC, $\mathrm{n}^{\circ} 2363$, et Inventaire d'anciens comptes..., $\mathrm{n}^{\circ}$ 134) - mais il est 
touchant aux finances: le chambellan de France Mathieu de Montmorency, Pierre V de Chambly et Hugues II de Bouville participent à l'audition des comptes de 1288 et $1289^{41}$; le même Pierre de Chambly et Enguerran de Marigny siègent à l'Échiquier de Normandie de Pâques $1305^{42}$, puis à celui de Pâques 1307 en compagnie du chambellan de France Mathieu de Trie ${ }^{43}$; Hugues II de Bouville est chargé d'asseoir des terres dues par le roi ${ }^{44} \ldots$

L'appétence particulière que manifestent les chambellans pour les finances ne les empêche cependant pas d'accomplir des commissions dans tous les domaines. Ils mènent ainsi des négociations diplomatiques, avec la Flandre ${ }^{45}$, la Castille ${ }^{46}$, l'Angleterre ${ }^{47}$ ou encore l'Empire ${ }^{48}$; de façon plus exceptionnelle, ils sont amenés à conduire des opérations militaires ${ }^{49}$. Ils

vrai qu'il s'agit là d'une fonction lucrative, que Pierre reçut peut-être à titre de sinécure -, puis maître des eaux et forêts sous Charles IV et Philippe VI, fonction qu'il exercera effectivement (ibid., $\mathrm{n}^{\circ} 2256$; Charles IV RTC, $\mathrm{n}^{\text {os }} 4759$ et 4887, et Philippe VI RTC, ${ }^{\text {os }} 1384$ et 1499).

41. Bibl. mun. Rouen, Leber 5870 (Menant), t. VIII, fol. 2.

42. Comptes royaux, $1285-1314 \ldots, \mathrm{n}^{\circ} 6475$.

43. BNF, lat. 12814, fol. 83v (sur la date de ce dernier acte, voir J. Favier, Un conseiller..., p. 101, n. 6 /p. 765, n. 104).

44. Philippe IV RTC, $\mathrm{n}^{\circ} 36$.

45. Sur les missions de Marigny en Flandre, voir J. Favier, Un conseiller..., p. 152-171 / 665-684 et p. 177-184/ 690-697.

46. Hugues II de Bouville est envoyé auprès du roi Sanche IV vers 1292 (Georges Daumet, Mémoires sur les relations de la France et de la Castille de 1255 à 1328, Paris, 1913, p. 112, n. 2).

47. Hugues II de Bouville, Pierre V et Pierre VI de Chambly sont témoins de la ratification du traité de Montreuil en 1299 (AN, J 632, nº 35). Hugues II de Bouville participe de nouveau à des négociations avec l'Angleterre en 1302 (AN, J 633, $\mathbf{n}^{\circ} 2$ ) ; Pierre V de Chambly lui aussi mène de nouvelles négociations en 1302 et 1303 (AN, JJ 35, n ${ }^{\circ}$ 34, et $\mathrm{J}$ 633, $\mathrm{n}^{\circ} 8 ; \mathrm{J} 633, \mathrm{n}^{\text {os }} 13$ et 15; Calendar of the patent rolls preserved in the Public Record Office [...], Edward I, t. IV : A. D. 1301-1307, Londres, 1898, p. 152 et 216). Enguerran de Marigny se rend quant à lui au moins deux fois en Angleterre, en 1308 et 1313 (National Archives, ex-Public Record Office, SC 1/34/7, et Calendar of the close rolls preserved in the Public Record Office [...], Edward II, t. II : A. D. 1313-1318, Londres, 1893, p. 42, 88, 44 et 45; à ce sujet, voir J. Favier, Un conseiller..., p. 120-127 / 632-638). Enfin, Hugues III de Bouville part en mission en Angleterre en 1323 (Foedera, conventiones, litterae, et cujuscunque generis acta publica inter reges Angliae et alios quosvis imperatores, reges..., éd. Thomas Rymer et Robert Sanderson, continué par Adam Clarke et Frederic Holbrooke, t. II, $1^{\text {re }}$ partie, Londres, 1818, p. 531).

48. En 1299, Mathieu de Montmorency effectue deux voyages en Champagne et en Lorraine pour rencontrer des émissaires allemands (Comptes royaux, 1285-1314..., $\mathrm{n}^{\text {os }} 3392$ et 3401).

49. Seul le chambellan de France Mathieu de Montmorency a eu une action militaire d'importance, en dirigeant la flotte royale en 1295 (AN, J 365, nº 1 ; voir également Inventaire d'anciens comptes..., $\mathrm{n}^{\text {os }} 2055,2330$ et 2397). Mais tous les chambellans ont régulièrement participé aux opérations militaires aux côtés du souverain (voir note 18 et texte correspondant). 
peuvent encore siéger de manière épisodique au Parlement ${ }^{50}$, voire, plus modestement, réaliser des enquêtes de justice ${ }^{51}$.

$\mathrm{Au}$ total, les chambellans sont loin d'être les officiers royaux qui reçoivent le plus de commissions : seules quatorze ont pu être répertoriées pour l'ensemble des chambellans de Philippe IV ${ }^{52}$, à l'exclusion de Marigny dont la situation est atypique ${ }^{53}$. C'est que le roi a besoin de ses chambellans auprès de lui. Mais l'importance et la variété des missions qui leur sont déléguées témoignent bel et bien de la confiance que leur accorde le souverain : les chambellans apparaissent tous comme ses conseillers naturels ${ }^{54}$.

Certes, tous les chambellans de Philippe IV n'ont probablement pas siégé au Conseil. Il est vrai que la participation des chambellans s'avère difficile à saisir, les documents relatifs à la composition du Conseil étant extrêmement rares ${ }^{55}$. Seuls trois d'entre eux y sont attestés sous Philippe IV: Hugues II de Bouville en 129556, le chambellan de France Mathieu de Trie en 1314,57 et, bien sûr, Enguerran de Marigny ${ }^{58}$. Au demeurant, même dans le cas de ce dernier, l'influence politique des cham-

50. Pierre V et Pierre VI de Chambly, ainsi qu'Hugues II de Bouville, sont présents à la cour en 1298 (comte Auguste-Arthur Beugnot, Les «Olim » ou registres des arrêts rendus par la Cour du roi sous les règnes de saint Louis, de Philippe le Hardi, de Philippe le Bel, de Louis le Hutin et de Philippe le Long, Paris, 1839-1844, 3 t. en 4 vol. [Collection des documents inédits sur l'histoire de France, $1^{\text {re }}$ série : Histoire politique], t. II, p. 423, $\left.\mathrm{n}^{\mathrm{o}} 13\right)$. Hugues III de Bouville, Jean de Machau et Mathieu de Trie participent à l'énonciation d'une sentence en juin 1310 (ibid., t. III, $1^{\text {re }}$ partie, p. 610, $\mathrm{n}^{\circ} 100$ ).

51. Une enquête effectuée par Pierre VII de Chambly est remise au roi en février 1316 (Boutaric, $\mathrm{n}^{\circ} 4646$, sous une date erronée).

52. Entre 1285 et 1314, le chambellan de France Mathieu de Montmorency reçoit trois commissions, Hugues II de Bouville et Pierre V de Chambly cinq chacun et Hugues III de Bouville une.

53. Il en reçoit au moins quatorze à lui seul, entre 1302 et 1314. Mais certains officiers, en particulier des maîtres du Parlement, en reçoivent bien plus encore : en quarante ans de carrière, Raoul de Joué s'en voit confier cinquante.

54. Les annales de Gand, parlant des «chambriers » du roi, affirment même que sic enim vocantur intimi consiliarii [regis] (Annales Gandenses, éd. Frantz Funck-Brentano, Paris, 1896 [Collection de textes pour servir à l'étude et à l'enseignement de l'histoire], p. 29, cité dans L.-L. Borrelli de Serres, Recherches..., t. II, p. 261).

55. O. Canteaut, Gouvernement..., t. I, p. 2-14.

56. AN, J 408, $\mathrm{n}^{\circ} 5$ (20 mars 1295).

57. AN, JJ 57, fol. 18 (19 janvier 1314). Cette présence au Conseil, ainsi que les nombreux dons qu'il reçut, n'invite pas à suivre Jean Favier lorsqu'il considère que le rôle de Mathieu fut mineur, qu'il était probablement tombé en disgrâce à la fin du règne de Philippe IV et qu'il s'était vu supplanté par Enguerran de Marigny (J. Favier, Un conseiller..., p. 74 / 585 et p. 203 / 717).

58. Il est notamment attesté au Conseil en 1313 (Jakob Schwalm, « Beiträge zur Reichsgeschichte des 14. Jahrhunderts aus dem Vaticanischen Archive », dans Neues Archiv der Gesellschaft für ältere deutsche Geschichtskunde zur Beförderung einer Gesamtausgabe der Quellenschriften deutscher Geschichte des Mittelalters, t. 25, 1900, p. 559-584, aux p. 564567) et en 1314 (AN, JJ 57, fol. 18). 
bellans est avant tout informelle et s'exerce principalement hors du Conseil 59. C'est ainsi qu'un ambassadeur pontifical rapporte qu'en 1313, Philippe IV, après une séance du Conseil, consulta en tête-à-tête Marigny, avant de prendre une décision allant à l'encontre de l'avis précédemment exprimé par le Conseil 60 .

Cette capacité de conseiller le souverain, quels que soient le lieu et les conditions de son exercice, se traduit concrètement par la participation des chambellans au commandement d'actes royaux. Les mentions hors teneur, dont l'usage se répand au cours du règne de Philippe IV ${ }^{61}$, nous révèlent en effet que presque tous les chambellans ont eu le pouvoir de commander des lettres royaux et l'ont exercé plus ou moins assidûment : la plupart d'entre eux ont ainsi commandé une poignée d'actes ${ }^{62}$, généralement des mesures gracieuses ${ }^{63}$ ou des mandats de paiement émis dans le cadre de leur action à

59. Ce constat prévaut dès le règne de Philippe III : Pierre de La Broce ne semble guère avoir siégé au Conseil, alors que son influence politique auprès du roi, qui se fonde prioritairement sur son accès privilégié au souverain, est indéniable (W. C. Jordan, «The struggle... », p. 442-443, et X. Hélary, «Pierre de La Broce...», p. 289-290; contra C.-V. Langlois, Le règne de Philippe III..., p. 20, qui présente son action politique comme insignifiante, car extérieure aux structures administratives). Au demeurant, la capacité de conseiller le souverain de manière informelle n'est en rien réservée aux chambellans : voir O. Canteaut, « Le roi de France gouverne-t-il par conseil ? L'exemple de Philippe V », dans Consulter, délibérer, décider: donner son avis au Moyen Âge (France-Espagne, VII ${ }^{\text {- }}$ $X V I^{e}$ siècle), éd. Martine Charageat et Corinne Leveleux-Teixeira, Toulouse, 2010 (Études médiévales ibériques), p. 157-176, aux p. 172-174..

60. J. Schwalm, «Beiträge...». Sur ce récit, voir O. Canteaut, «Le roi de France...», p. 172.

61. O. Canteaut, Gouvernement..., t. I, p. 53-54.

62. Pierre I de Machau ordonne l'expédition d'un acte royal en 1288 (AN, S 4076, $\mathrm{n}^{\circ}$ 27) et Jean de Machau de quatre de 1309 à 1314 (Philippe IV RTC, $\mathrm{n}^{\text {os }} 688,1399$, 1824 et 2113). Hugues II de Bouville participe au commandement de sept lettres royaux entre 1293 et 1303 (AN, K 36, nos 24 et 38; AN, J 178, n 55, J 460, no 21, J 218, $\mathrm{n}^{\circ} 23$; Arch. dép. Aube, 24 H cité dans É. Lalou, Itinéraire de Philippe IVle Bel, 1285-1314, Paris, 2007, 2 vol. [Mémoires de l'Académie des inscriptions et belles-lettres, 37], t. II, p. 184; AN, K 37, no 15 ; $\mathrm{AN}, \mathrm{P} 1394^{2}, \mathrm{n}^{\circ} 142$ bis), son fils Jean à celui de deux actes en 1306 et 1307 (AN, K 37, $\mathrm{n}^{\mathrm{o}} 33$, et $\mathrm{S} 5125^{\mathrm{B}}$, dossier 94, $\mathrm{n}^{\mathrm{o}}$ 59) et son fils Hugues III à celui d'un acte en 1313 (Philippe IV RTC, $\mathrm{n}^{\circ}$ 1990). Parmi les membres de la famille de Chambly, Pierre V commande au moins onze actes entre 1287 et 1304 (BNF, Picardie 311, no 56; AN, J 1020, n ${ }^{\circ} 10$; AN, K 177, $\mathrm{n}^{\circ} 230$; Arch. dép. Pas-de-Calais, A 42, $\mathrm{n}^{\circ} 17$; AN, J 1020, ${ }^{\circ} 12$; BNF, Clairambault 48, $\mathrm{n}^{\circ} 27$, et Clairambault $75, \mathrm{n}^{\circ} 170 ; \mathrm{AN}, \mathrm{J} 178, \mathrm{n}^{\circ} 56 ; \mathrm{AN}, \mathrm{L} 1050, \mathrm{n}^{\circ} 14$; $\mathrm{AN}, \mathrm{K} 37, \mathrm{n}^{\circ} 8$ bis $(\mathrm{a}, \mathrm{f})$; Arch. dép. Oise, H 718, cité dans É. Lalou, Itinéraire..., t. II, p. 245); son fils Pierre VI, seigneur de Viarmes, en commande deux de 1299 à 1307 (BNF, Clairambault 49, $\mathrm{n}^{\circ} 160$; Philippe IV RTC, $\mathrm{n}^{\circ}$ 906); et Pierre VII participe à l'expédition de six lettres royaux, entre 1310 et 1313 (Philippe IV RTC, n ${ }^{\text {os }} 1398,1553,1598,1978$, 1979 et 1991). Enfin le chambellan de France Mathieu de Trie commande six actes entre

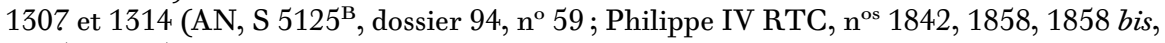
1865 et 2135).

63. Il s'agit avant tout de lettres de don (Philippe IV RTC, $\mathrm{n}^{\text {os }} 688$ et 1824 ; AN, J 178, $\mathrm{n}^{\text {os }} 55$ et $56, \mathrm{~J} 218, \mathrm{n}^{\circ} 23, \mathrm{~J} 1020, \mathrm{n}^{\circ} 12 ; \mathrm{AN}, \mathrm{P} 1394^{2}, \mathrm{n}^{\circ} 142$ bis; AN, S 4076, $\mathrm{n}^{\circ} 27$; Arch. dép. Pas-de-Calais, A 42, no 17 ; Arch. dép. Oise, H 718) ou de lettres d'amortissement, de 
l'Hôtel ${ }^{64}$; Enguerran de Marigny développe une activité beaucoup plus importante et variée ${ }^{65}$.

Il faut ajouter que les chambellans ont su user à leur propre profit du pouvoir ainsi acquis - ce qui a permis à ces hommes, tous issus de la petite noblesse ${ }^{66}$, de conforter leur ascension sociale ${ }^{67}$. L'opinion leur a d'ailleurs largement reproché tant leur emprise sur le roi que la fortune qu'ils ont accumulée ${ }^{68}$. De fait, les registres de la chancellerie regorgent de lettres en

franc-fief, ou encore d'autorisations d'aliéner (Philippe IV RTC, $\mathrm{n}^{\text {os }} 1399,1598$ et 1990 ; AN, J 460, $\mathrm{n}^{\circ} 21, \mathrm{~J} 1020, \mathrm{n}^{\circ} 10 ; \mathrm{AN}, \mathrm{K} 36, \mathrm{n}^{\text {os }} 24$ et $38, \mathrm{~K} 37, \mathrm{n}^{\text {os }} 8$ bis (a), 15 et 33;

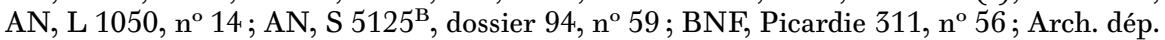
Aube, 24 $\mathrm{H}$ ).

64. BNF, Clairambault 48, $\mathrm{n}^{\circ} 27$; Clairambault $49, \mathrm{n}^{\circ} 160$, et Clairambault 75 , $\mathrm{n}^{\circ} 170$.

65. Nous sont parvenus au moins soixante-dix-huit actes royaux au commandement desquels Marigny a participé, entre mars 1305 et la mort de Philippe IV (BNF, Clairambault $48, \mathrm{n}^{\circ} 5 ; \mathrm{AN}, \mathrm{J} 390, \mathrm{n}^{\circ} 10$ ). Jean Favier répertorie et étudie soixante et onze de ces actes (J. Favier, Un conseiller..., p. 90-93 / 601-604).

66. Enguerran de Marigny est issu de la très petite noblesse normande (J. Favier, Un conseiller..., p. 9-11 /521-524). Quant aux Machau, leur famille est de rang chevaleresque au milieu du XIII ${ }^{\mathrm{e}}$ siècle, mais elle ne semble alors détenir aucune seigneurie (AN, J 208, Chambly, $n^{\circ}$ 2). Les Bouville apparaîtraient de leur côté au début du XIII ${ }^{\mathrm{e}}$ siècle comme seigneurs de Bouville (André du Chesne, Histoire de la maison de Chastillon..., Paris, 1621, p. 466). Les origines des Chambly sont sans doute plus prestigieuses, puisque leur famille est attestée dès le milieu du XII ${ }^{\mathrm{e}}$ siècle et serait dès cette date apparentée aux vicomtes de Beaumont, au service desquels ils se trouvent alors (Joseph Depoin, « La maison de Chambly sous les Capétiens directs », dans Bulletin philologique et historique (jusqu'à 1715) du Comité des travaux historiques et scientifiques, 1914, p. 117-162, aux p. 119-120).

67. Isabelle, fille d'Enguerran de Marigny, épouse ainsi Guillaume de Tancarville (Philippe IV RTC, $\mathrm{n}^{\circ}$ 1086), et son frère Louis la future héritière de l'importante châtellenie de Bapaume (Philippe VI RTC, $n^{\circ}$ 717) ; sur ces mariages, voir J. Favier, Un conseiller..., p. 2427 / 535-538. De son côté, Pierre V de Chambly marie son fils Pierre IX à Isabelle de Bourgogne (AN, J 208, Chambly, $\mathrm{n}^{\circ}$ 24), nièce du comte de Bourgogne Otton IV (BNF, fr. 31908, fol. 77v et le P. Anselme, Histoire généalogique..., t. VIII, p. 415-416) et cousine par alliance de Philippe V (Boutaric, $\mathrm{n}^{\circ}$ 6153). Quant à Jean de Bouville, il épouse en 1293 Marguerite de Bommiers (BNF, Baluze 54, fol. 184-185), apparentée aux Sully (É. Richemond, Recherches généalogiques..., t. II, planche entre les p. 96 et 97); celle-ci se remariera avec le comte de Roucy (Philippe V RTC, $\mathrm{n}^{\circ}$ 3452).

68. Les critiques à l'encontre de Marigny sont particulièrement nombreuses (voir J. Favier, Un conseiller..., p. 195-199 / 709-713). De semblables accusations ne sont pas neuves : ce sont peut-être les chambellans de Louis IX qui se cachent derrière les animaux concussionnaires mis en scène par Rubeteuf dans Renart le Bestourné (Rutebeuf, Euvres complètes, éd. Edmond Faral et Julia Bastin, Paris, 1959, 2 vol., t. I, p. 537-544, en particulier p. 542-543, v. 110-127; sur cette lecture, voir notamment ibid., p. 533-536, et Les comptes [...] de Jean Sarrazin..., p. 30). Trois textes brefs écrits à l'encontre de Pierre de La Broce nous sont également parvenus (Frédéric-Édouard Schneegans, « Trois poèmes de la fin du XIII ${ }^{\mathrm{e}}$ siècle sur Pierre de La Broce », dans Romania, t. 58, 1932, p. 520-550 ; pour un commentaire du troisième d'entre eux, voir W. C. Jordan, « The struggle... », p. 459-462). Plutôt que de relayer les critiques émanant de l'opinion, ces derniers, écrits dans un but de propagande, seraient destinés à justifier a posteriori la condamnation de Pierre (Nancy 
faveur de Marigny, des Bouville, des Chambly ${ }^{69}$; il en va de même du Livre rouge, où la Chambre des comptes consigne les dons royaux sous Philippe IV ${ }^{70}$, et qui contient plus de $6 \%$ d'actes à leur profit ${ }^{71}$; et certaines chartes que leur concède le roi font même preuve d'une solennité remarquable ${ }^{72}$. Plus que quiconque, les chambellans ont ainsi bénéficié des largesses royales ${ }^{73}$. Il est vrai que, dans la mesure où ils fréquentent quotidiennement le souverain et où celui-ci leur confiera même le soin d'intervenir dans le traitement des requêtes qui lui sont soumises ${ }^{74}$, ils sont idéalement placés pour présenter à leur tour des demandes et en obtenir la satisfaction ${ }^{75}$. Ils ont ainsi pu se constituer des domaines fonciers remarquables,

Freeman Regalado, Poetic patterns in Rutebeuf: a study in non-courtly poetic modes of the thirteenth century, New Haven, 1971, p. 86-87).

69. On y recense plus d'une vingtaine de dons en faveur d'Enguerran de Marigny. Quant aux Chambly, les seuls Pierre V, Pierre VI et Pierre VII de Chambly y sont mentionnés dans trente-deux actes différents ; bien d'autres membres de leur famille font également l'objet de lettres royaux. Les Bouville et les Machau y sont moins bien représentés, car Pierre I de Machau et Hugues II de Bouville sont décédés avant que l'enregistrement en chancellerie ne prenne un caractère systématique.

70. Sur ce document, voir $\mathrm{O}$. Canteaut, «Une première expérience d'enregistrement des actes royaux sous Philippe le Bel : le Livre rouge de la Chambre des comptes », dans Bibliothèque de l'École des chartes, t. 160, 2002, p. 53-78, et l'essai de restitution qu'en fournit C.-V. Langlois (« Registres perdus des archives de la chambre des comptes de Paris », dans Notices et extraits des manuscrits de la Bibliothèque nationale et autres bibliothèques publiés par l'Académie des inscriptions et belles-lettres, t. 40,1916, p. 283-398).

71. Les cahiers relatifs aux dons à héritage et aux dons à vie et à volonté établis durant le règne de Philippe IV contiennent huit cent douze actes (voir O. Canteaut, «Une première expérience... », p. 61-64). Or on n'y rencontre pas moins de douze actes concernant Pierre V de Chambly, quinze Pierre VI, un Pierre VII, quatre Hugues II de Bouville, un Hugues III et dix-huit Enguerran de Marigny. Précisons cependant que les dons royaux ne constituent qu'une minorité de ces actes - à l'exception notable de ceux en faveur de Marigny -, les deux tiers d'entre eux consistant en actes d'échange ou d'achat, tant avec le roi qu'avec les bénéficiaires de dons royaux antérieurs. Sur l'importance de cette politique d'achats et d'échanges, voir note 76 .

72. Deux actes concédés à Pierre $\mathrm{V}$ de Chambly sont ainsi pourvus d'enluminures spectaculaires (AN, J 208, Chambly, $\mathrm{n}^{\text {os }} 1$ et 3). De la même manière, les actes en faveur de certains chambellans revêtent fréquemment la forme, pourtant exceptionnelle, de diplômes solennels : Pierre de La Broce était ainsi le bénéficiaire du seul diplôme original de Philippe III qui nous soit parvenu (C.-V. Langlois, Le règne de Philippe III..., p. 18, n. 6) et pas moins de quatre diplômes de Philippe IV ont été émis en faveur d'Hugues III de Bouville (Philippe IV RTC, $\mathrm{n}^{\text {os }} 1479,1572,1588$ et 2053).

73. Ce constat prévaut déjà pour Pierre de La Broce, ce dont témoigne son très volumineux chartrier (AN, J 726 à $\mathrm{J}$ 730), ainsi qu'un inventaire dressé sans doute peu après sa chute et qui énumère au moins une cinquantaine d'actes royaux en sa faveur (AN, J 730, $\mathrm{n}^{\circ} 223$; voir C.-V. Langlois, Le règne de Philippe III..., p. 16).

74. Voir note 28 et texte correspondant.

75. Les officiers de l'Hôtel seront d'ailleurs les premiers visés, dans la seconde moitié du $\mathrm{XIV}^{\mathrm{e}}$ siècle, par les critiques et par la réglementation contre les requérants importuns (Olivier Mattéoni, «"Plaise au roi" : les requêtes des officiers en France à la fin du Moyen Âge », dans Suppliques et requêtes : le gouvernement par la grâce en Occident, $X I I^{e}-X V^{e}$ siècle, éd. 
grâce à une politique très habile d'échanges et de dons ${ }^{76}$. Enguerran de Marigny se crée une véritable baronnie autour de Mainneville, Marigny, Écouis et Longueville en Normandie ${ }^{77}$; à une moindre échelle, les Chambly font de même, toujours en Normandie, autour de Quatremare, où Pierre V fait installer dans son manoir des reliques de saint Louis ${ }^{78}$, mais aussi en Vexin dans les environs de Chambly ${ }^{79}$; les Bouville et les Machau agissent à l'identique en Gâtinais ${ }^{80}$.

Les chambellans ne se sont pas contentés d'asseoir la fortune de leur famille; ils ont aussi su faire perdurer leur influence auprès du roi. Ils sont ainsi parvenus à infléchir durablement à leur profit le recrutement de leurs collègues et, plus largement, du personnel de l'Hôtel pour y imposer leur

Hélène Millet, Rome, 2003 [Collection de l'École française de Rome, 310], p. 281-296, aux p. 282-286).

76. Plus que des dons gratuits, le roi concède à ses chambellans des échanges et des assignations avantageux, sur le plan financier comme sur le plan symbolique; ou encore il les autorise à faire des acquisitions, en particulier auprès d'autres bénéficiaires de ses largesses (voir note 71). De fait, comme le remarque J. Favier à propos d'Enguerran de Marigny, « la fortune du chambellan ne lui a pas été donnée par le roi, mais seulement les moyens de l'acquérir » (Un conseiller..., p. 43 / 552). Par là les chambellans ne font pas exception dans l'entourage du roi (voir par exemple, à la même époque, le cas de Philippe le Convers décrit dans Franklin J. Pegues, The lawyers of the last Capetians, Princeton, 1962, p. 132133).

77. Le fief de Marigny (Seine-Maritime, arr. Dieppe, cant. Gournay-en-Bray, comm. Dampierre-en-Bray), complété par ceux de Mainneville, Gaillefontaine, Vascœuil et Fontaine-Châtel, fut érigé en baronnie en décembre 1313 (Philippe IV RTC, nº 2069). Sur les domaines d'Enguerran et leur constitution, voir J. Favier, Un conseiller..., p. 33-39 / 543549 .

78. Pierre acquiert Quatremare (Eure, arr. Les Andelys, cant. Louviers-Sud) par échange avec le roi en 1286 (AN, J 208, Chambly, $\mathrm{n}^{\text {os }} 5$ et 25); il y fonde avant 1305 une chapelle en l'honneur de saint Louis (Regestum Clementis papae V ex Vaticanis archetypis [...] nunc primum editum cura et studio monachorum ordinis sancti Benedicti, Rome, 18851888,9 vol., t. I, $\mathrm{n}^{\circ} 432$ ), témoignant ainsi de sa dévotion pour son ancien maître. Il avait d'ailleurs participé au procès de canonisation de ce dernier (Louis Carolus-Barré, Le procès de canonisation de saint Louis (1272-1297) : essai de reconstitution, Rome, 1994 [Collection de l'École française de Rome, 195], p. 89-90). Les reliques de saint Louis qu'il avait placées dans la chapelle de Quatremare furent saisies par Philippe $\mathrm{V}$ avec l'ensemble du domaine (Boutaric, $\mathrm{n}^{\circ}$ 6799).

79. Ils détiennent en particulier des biens à Chambly (Oise, arr. Senlis, cant. Neuilly-enThelle), Crouy-en-Thelle (ibid.), Persan (Val-d'Oise, arr. Pontoise, cant. Beaumont-surOise), Neaufles-Saint-Martin (Eure, arr. Les Andelys, cant. Gisors) et Viarmes (Val-d'Oise, arr. Sarcelles, ch.-l. cant.). Voir notamment Philippe IV RTC, $\mathrm{n}^{\text {os }} 1298$ et 979.

80. L'essentiel des possessions des Bouville sont concentrées au nord du Gâtinais, autour de Milly-la-Forêt (Essonne, arr. Évry, ch.-l. cant.), Bouville (Essonne, arr. et cant. Étampes), Farcheville (ibid., comm. Bouville) et La Chapelle-la-Reine (Seine-et-Marne, arr. Fontainebleau, ch.-l. cant.) ; voir notamment le partage successoral d'Hugues II dans Philippe IV RTC, $\mathrm{n}^{\circ}$ 507. De leur côté, les Machau sont possessionnés à l'autre extrémité du Gâtinais, à Châlette-sur-Loing (Loiret, arr. Montargis, ch.-l. cant.) et Villemandeur (Loiret, arr. Montargis, cant. Amilly), ainsi qu'à Fay-aux-Loges (Loiret, arr. Orléans, cant. Châteauneuf-surLoire); voir notamment Philippe V RTC, n 2755, et AN, Q $^{1} 569$. 
parentèle et leurs clients. Dès leur plus jeune âge, leurs enfants sont devenus valets de l'Hôtel, achevant là leur formation ${ }^{81}$, avant d'être faits chambellans à leur tour ${ }^{82}$. Les structures financières de l'Hôtel sont, elles aussi, en partie dominées par leur réseau de relations : un frère de Pierre $\mathrm{V}$ de Chambly, Oudard ${ }^{83}$, siège dans les années 1290 à la Chambre aux deniers ${ }^{84}$, et les comptes de la Chambre sont tenus, à partir de 1307, par un clerc de Marigny ${ }^{85}$. Enfin, leur vaste parentèle peuple l'Hôtel, dans des fonctions domestiques plus ou moins prestigieuses: valet ${ }^{86}$, sergent ${ }^{87}$,

81. Sur la fonction de valet de l'Hôtel, voir O. Canteaut, Gouvernement..., t. II, p. 372 .

82. Jean et Pierre II de Machau commencent leur carrière comme valets à l'Hôtel en 1289 (Les comptes [...] de la Chambre aux deniers..., p. 853 et 854, appendice, $\mathrm{n}^{\text {os }} 39$ et 42). Pierre VII de Chambly apparaît dans la même fonction en 1299 (ibid., p. 459, CO VIII, $\mathrm{n}^{\circ}$ 50). Il y côtoie à compter de 1301 Jean et Hugues III de Bouville, fils d'Hugues II (ibid., p. 458, CO VIII, $\mathrm{n}^{\circ} 46$ ). Un autre fils d'Hugues II, Jean dit de Navarre (Philippe IV RTC, $\mathrm{n}^{\circ}$ 402), est également valet de l'Hôtel en 1313 (Les comptes [...] de la Chambre aux deniers..., p. 869, appendice, $\mathrm{n}^{\circ}$ 97), et Guillaume, fils de Pierre I de Machau, sert le roi comme valet de chambre à compter de 1308 (Philippe IV RTC, $\mathrm{n}^{\circ}$ 549); mais aucun de ces deux derniers ne deviendra chambellan. Enfin Louis de Marigny, fils d'Enguerran et futur chambellan sous Louis X (voir annexe), est valet du roi en 1312 (Philippe IV RTC, $\mathrm{n}^{\circ}$ 1693).

83. Bibl. mun. Rouen, Leber 5870 (Menant), t. VIII, fol. 2. C'est à tort qu'Oudard est indiqué comme fils de Pierre V par J. Depoin («La maison de Chambly... », p. 144).

84. Ordonnance du Bois de Vincennes, janvier 1291, art. 109, AN, JJ 57, fol. 17, et BNF, lat. 12814, fol. 67v ([1291-1292]).

85. Il s'agit de Michel de Bourdenay, dont les liens avec Marigny sont bien documentés (voir notamment Louis X RTC, $\mathrm{n}^{\circ} 16$ ). Son rôle à l'Hôtel a en revanche fait l'objet d'appréciations diverses - il est vrai qu'il remplit des missions financières nombreuses - : d'après les Filiations de la Chambre des comptes, il fut maître de la Chambre aux deniers du roi (AN, P 2635, fol. 42) ; le colonel Borrelli de Serres puis J. Viard le disent argentier du roi (L.-L. Borrelli de Serres, Recherches..., t. III, p. 208; Philippe IV JT, col. 852, $\mathrm{n}^{\circ} 5865$, n. 1) ; É. Lalou semble quant à elle considérer qu'il fut chambellan (« Enguerran de Marigny et l'évolution du métier de la Chambre du roi », dans Finances, pouvoirs et mémoire : mélanges offerts à Jean Favier, éd. Jean Kerhervé et Albert Rigaudière, Paris, 1999, p. 269278, à la p. 275). En réalité, les comptes qu'il nous a laissés à partir de 1307 (Comptes royaux, 1285-1314..., t. II, $\mathrm{n}^{\text {os }} 23966$ à 24100), ainsi que la description de son rôle faite au moment de la vérification des comptes de Marigny en 1315 (Louis X RTC, $\mathrm{n}^{\circ}$ 16), laissent peu de place au doute : il s'occupait de la gestion financière de la Chambre, rôle que jouera ultérieurement l'argentier (sur la création de l'argenterie, voir note 105). Toutefois, c'est par erreur que le colonel Borrelli de Serres lui attribue cette fonction à partir de 1305 (L.-L. Borrelli de Serres, Recherches..., t. III, p. 208, contra ibid., p. 55, note 2).

86. Voir notamment notes 82 et 91 .

87. Un Jean de Bouville, dont nous ignorons les liens de parenté avec Hugues II, occupe cette fonction dans l'Hôtel du roi en 1289 (Les comptes [...] de la Chambre aux deniers..., p. 857, appendice, $\mathrm{n}^{\circ}$ 75). Jacques de Chambly est quant à lui huissier de salle en 1322 (BNF, fr. 7855, p. 278 et 284); il devient fourrier de l'Hôtel jusqu'à la fin du règne de Philippe VI (BNF, fr. 7855, p. 305 et 441; Philippe VI JT, n 3161). Enfin André Thiard, qui cousine probablement avec Pierre V de Chambly (J. Depoin, «La maison de Chambly... », p. 123-124), est huissier d'armes du roi sous Philippe V et Charles IV (AN, JJ 57, fol. 59v ; Charles IV JT, no 446). 
panetier du roi ${ }^{88}$, chambellan d'un prince ${ }^{89}$... Les Chambly sont assurément passés maîtres dans ce domaine : quatre d'entre eux se sont côtoyés ou succédé comme chambellans ${ }^{90}$; les différents membres de leur très nombreuse parentèle fourmillent à l'Hôtel ${ }^{91}$, et un de leurs clercs est devenu notaire du roi ${ }^{92}$. Mais les chambellans issus des familles de Bouville et de Machau - trois pour chacune d'entre elles - n'ont guère lieu de les envier ${ }^{93}$. Marigny lui-même parvient à faire de son fils Louis un chambellan en 1314, ${ }^{94}$. Qui plus est, toutes ces familles sont unies entre elles par des alliances matrimoniales ${ }^{95}$. La constitution de dynasties de chambellans, ébau-

88. André Thiard de Chambly - peut-être le même que l'huissier de Philippe V et de Charles IV (voir note précédente) - est panetier du roi et de la reine en 1301 (Philippe IV JT, $\mathrm{n}^{\circ}$ 5544) et panetier de la reine en 1304 (BNF, lat. 5462, p. 366). Robert de Machau est panetier de Philippe IV de 1309 à 1311 (Philippe IV RTC, ${ }^{\text {os }}$ 644 et 1302). Jean de Bouville - peut-être l'ancien sergent de 1289 (voir note précédente) - est également panetier de Charles IV de 1322 à 1326 (BNF, fr. 7855, p. 270 et 305).

89. Pèlerin de Chambly, demi-frère de Pierre V (voir $\mathrm{AN}, \mathrm{K} 177$, $\mathrm{n}^{\circ} 230$, et L. CarolusBarré, Le procès..., p. 176, corrigeant J. Depoin, « La maison de Chambly... », p. 155-156), est chambellan de Charles de Valois en 1289 (Charles IV RTC, ${ }^{\circ} 5286$; original, AN, K 36, $\mathrm{n}^{\circ}$ 17). Son père Pierre de Laon, ancien chambellan de Louis IX («Vie de saint Louis par le confesseur de la reine Marguerite », dans Recueil des historiens des Gaules et de la France, t. XX, éd. Pierre-Claude-François Daunou et Joseph Naudet, Paris, 1840, p. 58-121, à la p. 112 ; BNF, lat. 5470, fol. 211), avait quant à lui assuré la garde des enfants royaux sous Philippe III (Guillaume de Chartres, « De vita et actibus inclitae recordationis regis Francorum Ludovici et de miraculis quae ad ejus sanctitatis declarationem contigerunt », dans Recueil des historiens des Gaules..., t. XX, p. 27-41, à la p. 39) et avait peut-être été lui aussi chambellan de Charles de Valois (BNF, lat. 11003, fol. 111v : «Peregrinus de Chambliaco, [...] filius Petri de Lauduno, dilecti militis nostri, quondam karissimi fratris nostri Caroli cambellani »- à moins que cette attestation isolée ne doive être corrigée, de « cambellani » en « cambellanus »).

90. Voir annexe.

91. En 1289, au moins cinq membres de l'Hôtel portent le patronyme de Chambly : Jean, clerc du Temple ; Martin, valet ; Robert, maître des sommiers ; Eudes, valet de la fruiterie ; et Pierre, valet de cuisine (Les comptes [...] de la Chambre aux deniers..., p. 851-856, appendice, $\mathrm{n}^{\text {os }} 26,40,54,60$ et 64). En 1313, ils sont encore cinq à porter ce nom : Jacquet, Jean, Philippot et Thiard, tous quatre valets, et Pierre IX, familier du roi de Navarre (ibid., p. 870874, appendice, $\mathrm{n}^{\text {os }} 97,101,104$ et 121$)$.

92. Il s'agit de Pierre d'Aubigny, clerc de Pierre VI de Chambly en 1298 (Philippe IV JT, $\mathrm{n}^{\circ}$ 409) et notaire du roi de 1300 à 1323 (O. Canteaut, «Du notaire au clerc du secret: le personnel de la chancellerie des derniers Capétiens directs dans les rouages du pouvoir », dans De part et d'autre des Alpes, II : Chancelleries et chanceliers des princes à la fin du Moyen Âge, actes de la table ronde internationale de Chambéry, 5 et 6 octobre 2006, éd. Guido Castelnuovo et Olivier Mattéoni, à paraître).

93. Voir annexe.

94. Voir annexe.

95. Pierre VI de Chambly a ainsi épousé avant 1277 Jeanne, fille de Pierre I de Machau (AN, J 208, Chambly, $\mathrm{n}^{\circ}$ 2). Hugues II de Bouville a épousé en 1283 Marie, fille d'Oudard de Chambly (BNF, Baluze 54, fol. 183v) et nièce de Pierre V de Chambly (voir note 83). Pèlerin de Chambly, demi-frère de Pierre V (voir note 89), est marié en 1291 à Isabelle, fille du chambellan Jean Poucin (BNF, lat. 11003, fol. 111v). En revanche, c'est apparemment à 
chée tout au long du $\mathrm{XIII}^{\mathrm{e}}$ siècle ${ }^{96}$, se voit ainsi parachevée sous Philippe IV : le monde de l'Hôtel, où la reproduction sociale est déjà très forte ${ }^{97}$, est alors dominé par le groupe plus fermé encore des chambellans ${ }^{98}$.

Or cette domination se délite rapidement à partir de la chute d'Enguerran de Marigny en 1315. Certes, celui-ci est le moins lié de tous au groupe formé par les chambellans : à son entrée à la Chambre en 1305, il n'avait

tort qu'André du Chesne a affirmé que Jean de Bouville, fils d'Hugues II et futur chambellan, avait épousé en 1293 une héritière des Villebéon (É. Richemond, Recherches généalogiques..., t. II, p. 96, n. 1 ; sur les Villebéon, voir note suivante).

96. À son entrée à la Chambre, sans doute en 1269 , Pierre $\mathrm{V}$ de Chambly était déjà apparenté à trois des chambellans du roi : Pierre de Villebéon, chambellan de 1255 à 1270 (É. Richemond, Recherches généalogiques..., t. II, p. 119 et 123), descendant d'une longue lignée de chambellans royaux (voir notamment le P. Anselme, Histoire généalogique..., t. VIII, p. 438-439) et parent de la mère de Pierre V (L. Carolus-Barré, Le procès..., p. 124; voir également J. Depoin, «La maison de Chambly... », p. 129) ; Pierre Tristan, lui aussi membre d'une lignée de chambellans (Henri Stein, «Pierre Tristan, chambellan de Philippe Auguste, et sa famille », dans Bibliothèque de l'École des chartes, t. 78, 1917, p. 135153, à la p. 136), dont Pierre V épousa la fille dans les années 1260 (J. Depoin, « La maison de Chambly... », p. 129); et enfin Pierre de Laon, son beau-père (voir note 89). Pierre V était en outre fils ou petit-fils d'un chambellan de Blanche de Castille (L. Carolus-Barré, Le procès..., p. 175, corrigeant J. Depoin, « La maison de Chambly... », p. 121).

97. Voir O. Canteaut, Gouvernement..., t. II, p. 463-465. Au demeurant, cette situation ne semble pas le propre de l'Hôtel des derniers Capétiens ; en témoigne par exemple l'Hôtel du roi de Castille Sanche IV à la même époque (Sophie Coussemacker, «Compter et payer les hommes de la Maison de Sanche IV (1292-1294)», communication à la journée d'étude «Entre ambitions princières, idéal de gouvernement et principe de réalité : les effectifs des serviteurs princiers et royaux à la fin du Moyen Âge », Limoges, 6 novembre 2009, à paraître).

98. Les chambellans du roi issus des familles de Machau et de Bouville ont tous reçu cet office après avoir contracté des mariages avec des membres de la famille de Chambly (voir note 95) - même si Hugues II de Bouville était déjà chambellan du fils du roi lorsqu'il épousa Marie de Chambly (BNF, Baluze 54, fol. 183v). Seuls Enguerran de Marigny et les chambellans de France Mathieu de Montmorency et Mathieu de Trie ont gagné la Chambre sous Philippe IV sans avoir au préalable noué d'alliance matrimoniale avec leurs collègues. Encore la situation des deux derniers nommés est-elle liée à la différence de recrutement social entre les chambellans de France et les chambellans du roi (voir note 9). Quant à Marigny, il n'est pas impossible qu'il ait eu des liens de familiarité anciens avec d'autres chambellans, mais ni son rôle d'écuyer d'Hugues II de Bouville (J. Favier, Un conseiller..., p. 57 / 567, citant le P. Anselme avec une référence erronée), ni son office de sergent du même Hugues (La chronique métrique attribuée à Geoffroy de Paris, éd. Armel Diverrès, Paris, 1956 [Publications de la faculté des lettres de l'université de Strasbourg, 129], p. 209, v. 6284-6285) ne sont indubitables. En effet la Chronique métrique, ouvertement hostile à Marigny (voir note 102), tient manifestement là des propos inexacts et infamants contre ce dernier; quant aux indications du P. Anselme, elles pourraient s'inspirer plus ou moins directement de cette chronique. 
pour tout parent dans l'entourage royal qu'un chevalier de l'Hôtel ${ }^{99}$, et s'il avait su depuis faire entrer sa parentèle à ses côtés ${ }^{100}$ et nouer des liens, notamment familiaux, avec ses collègues à la Chambre ${ }^{101}$, il est possible que la faveur royale lui ait attiré l'animosité de ceux-ci ${ }^{102}$. Quant aux pouvoirs financiers qu'il avait pu accumuler, s'ils échappent en 1315 aux chambellans ${ }^{103}$, ils étaient à la vérité attachés à la personne de Marigny, et non à son office ${ }^{104}$. Tout au plus peut-on remarquer qu'avec le remplacement du

99. Il cousine avec la famille de Flavacourt (BNF, Clairambault 48, $\mathrm{n}^{\circ} 28$, et Philippe IV $\mathrm{JT}, \mathrm{n}^{\circ}$ 2614), dont un représentant, Guillaume, seigneur de Flavacourt, est chevalier de l'Hôtel dès 1301 (Les comptes [...] de la Chambre aux deniers..., p. 292, CO II, nº 31), puis maître de l'Hôtel à partir de 1311 (Philippe IV RTC, $\mathrm{n}^{\circ}$ 1404).

100. Son fils Louis est valet du roi en 1312 (Philippe IV RTC, $\mathrm{n}^{\circ}$ 1693) et deviendra chambellan à la mort de Philippe IV (voir annexe) ; son demi-frère Oyselet est échanson du roi de Navarre depuis 1307 (BNF, fr. 7855, p. 120). La Chronique métrique, tout en évoquant clairement le népotisme de Marigny, tend cependant à l'exagérer, affirmant que «mestres fist a court » et «chambellans en la court le roy mist il ans 》 (La chronique métrique..., p. 210, v. 6296 et 6297-6298).

101. Dès 1308, il est nommé exécuteur testamentaire de son collègue Jean de Bouville (BNF, Baluze 54, fol. 205-v). Mais surtout il marie sa fille à Guillaume de Tancarville en 1309; or celui-ci a pour tante Isabelle de Rosny, femme de Pierre V de Chambly (Jean Favier, Cartulaire et actes d'Enguerran de Marigny, Paris, 1965 [Collection de documents inédits sur l'histoire de France, série in-8 $\left.{ }^{\circ}, 2\right]$, no 122, p. 263-264). Remarquons que Marigny a reproduit les stratégies matrimoniales élaborées par Pierre de La Broce trente ans plus tôt : alors qu'il ne possédait aucun lien de parenté avec ses collègues, il a profité de son influence pour marier sa fille avec un membre de la famille de Villebéon (C.-V. Langlois, Le règne de Philippe III..., p. 19).

102. Alors que Marigny est violemment pris à partie par l'auteur de la Chronique métrique (par exemple, p. 196-197, v. 5541-5618), l'attitude d'Hugues II de Bouville et de Pierre V de Chambly à Courtrai, puis la politique du même Hugues, y sont louées (ibid., p. 122, v. 1594-1597, et p. 209, v. 6285-6287). Sans doute faut-il voir dans cette différence de traitement la traduction de liens entre Charles de Valois, dans l'entourage duquel cette chronique a été composée (Jean Dunbabin, « The metrical chronicle traditionally ascribed to Geffroy de Paris », dans Fauvel studies: allegory, chronicle, music and image in Paris, Bibliothèque nationale, ms. français 146, éd. Margaret Bent et Andrew Wathey, Oxford, 1998, p. 233-246, aux p. 241-242), et les familles de Chambly et de Bouville. En effet Pèlerin de Chambly, demi-frère de Pierre V, a été au service de Charles de Valois (voir note 89) et l'on trouve, parmi les actes royaux commandés par Pierre V de Chambly et par Hugues II de Bouville, deux dons en faveur du frère du roi (AN, $\mathrm{J} 178, \mathrm{n}^{\text {os }} 55$ et 56).

103. É. Lalou, « Enguerran de Marigny... », p. 275-276.

104. Voir notamment J. Favier, Un conseiller..., p. 70-71 / 580-581 et p. 109 / 620. Il paraît donc excessif de considérer, comme É. Lalou («Enguerran de Marigny... », p. 274276), que les fonctions financières exercées par Enguerran de Marigny auraient perduré après sa chute et, qu'échappant désormais aux chambellans, elles auraient été confiées au souverain du Trésor. Si l'organisation du Trésor établie en janvier 1317 au profit du souverain du Trésor Henri de Sully n'est pas sans rappeler celle qui fut constituée en janvier 1314 au profit d'Enguerran de Marigny, puisque les deux hommes s'y voient autorisés à ordonnancer des dépenses, elle n'offre pas à Henri de Sully le même pouvoir exclusif sur les finances que celui qu'avait pu détenir Marigny : là où, en 1314, seuls le roi et Marigny pouvaient ordonner des dépenses, par lettres scellées de leur signet personnel, de simples lettres royales, éventuellement commandées par un conseiller du roi, suffisent d'après 
clerc de Marigny qui tenait les comptes de la Chambre par un nouvel officier, l'argentier, recruté au sein de la bourgeoisie et lié à la Chambre des comptes, la maîtrise des finances de la Chambre échappe désormais aux chambellans ${ }^{105}$. Mais la situation des Machau, des Chambly et des Bouville, qui restent tous en fonction sous Louis $X$, n'apparaît en rien ébranlée par l'exécution d'Enguerran de Marigny.

Pourtant, ces familles ne sont plus seules à la tête de la Chambre. En effet Louis X crée au moins onze nouveaux chambellans ${ }^{106}$, issus pour plus de la moitié de son propre Hôtel ${ }^{107}$. L'effectif des chambellans du roi passe au total de quatre à treize ${ }^{108}$, inflation qui contribue sans nul doute à diluer le pouvoir de chacun, et en particulier celui des dynasties en place jusque-là. Car si un tiers des nouveaux venus appartiennent encore à ces familles ${ }^{109}$,

l'ordonnance de 1317 (voir AN, JJ 57, fol. 19-v et Ordonnances des roys de France..., t. I, p. 628 , art. 1).

105. Jean Billouard est le premier à porter le titre d'argentier, à partir de février 1316 (Comptes du Trésor..., $\mathrm{n}^{\circ}$ 854); il est nommé en même temps maître de la Chambre des comptes (ibid., $\mathrm{n}^{\circ}$ 783). Jean semble être d'origine modeste, mais il s'agrège rapidement à la bourgeoisie parisienne, portant le titre de bourgeois de Paris dès 1317 (AN, $\mathrm{J} 1036, \mathrm{n}^{\circ}$ 7) et épousant en 1322 une Marcel, veuve de deux grands bourgeois (Jean XXII, 1316-1334: lettres communes analysées d'après les registres dits d'Avignon et du Vatican, éd. Guillaume Mollat, Paris, 1904-1947, 16 vol. [Bibliothèque des Écoles françaises d'Athènes et de Rome, $3^{\mathrm{e}}$ série, 1 bis $], \mathrm{n}^{\mathrm{o}} 15476$ ) ; à aucun moment il ne se liera avec le personnel de la Chambre. En dépit de la nomination de cet argentier, le chambellan Hugues d'Augeron s'occupe encore probablement des comptes de la Chambre, et assurément des joyaux, jusqu'à la mort de Louis X (Philippe V RTC, $\mathrm{n}^{\circ} 1707$; voir également les paiements effectués par Hugues dans Comptes royaux, 1314-1328, éd. F. Maillard, dir. R. Fawtier, Paris, 1961, 2 vol. [Recueil des historiens de la France, Documents financiers, 4], ${ }^{\text {os }} 12493$ et 14442, et dans Comptes du Trésor..., $\mathrm{n}^{\circ}$ 864) et il continue à avoir la garde des joyaux jusqu'au début de l'année 1317, alors qu'il n'est même plus chambellan (Comptes de l'argenterie..., p. 15).

106. Voir annexe.

107. Hugues d'Augeron est attesté comme chambellan de Louis dès 1299 (Philippe IV $\mathrm{JT}, \mathrm{n}^{\circ}$ 3844) ; Guillaume Paumier l'est depuis 1307 (Les comptes [...] de la Chambre aux deniers..., p. 801, CE I, $\mathrm{n}^{\circ} 547$; voir également Philippe IV RTC, $\left.\mathrm{n}^{\circ} 1034\right)$; Gilles de Sergines le devient avant 1311 (BNF, fr. 7855, p. 117, ordonnance de l'Hôtel du roi de Navarre, dont le terminus ante quem est fourni par l'élection de Raoul Rousselet comme évêque); enfin Pierre IX de Chambly est chambellan de Louis depuis 1311 (AN, J 208, Chambly, $\mathrm{n}^{\circ}$ 24). Avant 1311, Eudes de Vaussemain est également entré à l'Hôtel de Louis de Navarre en tant que chevalier (BNF, fr. 7855, p. 117) et Philippe de Saint-Martin en tant que panetier (ibid., p. 120). En revanche, aucun document ne permet d'attester que Louis de Marigny fût chambellan de Louis X avant l'avènement de ce dernier (contra J. Favier, Un conseiller..., p. 13 / 525, p. 29 / 539 et p. 83 / 594).

108. Tel est le nombre de chambellans du roi nommés dans le testament de Louis $\mathrm{X}$ en juin $1316\left(\mathrm{AN}, \mathrm{J} 404^{\mathrm{A}}, \mathrm{n}^{\circ} 22\right)$.

109. Pierre IX de Chambly est le fils de Pierre V et le demi-frère de Pierre VI (Philippe IV RTC, $\mathrm{n}^{\circ}$ 1298). Pierre II de Machau est le frère de Jean de Machau et le beau-frère de Pierre VI de Chambly (Philippe V RTC, $\mathrm{n}^{\circ}$ 2755). Louis de Marigny est le fils aîné d'Enguerran (Philippe IV RTC, $n^{\circ}$ 717). Enfin Pierre de Saint-Martin épouse la fille de Pierre II de Machau (Philippe V RTC, $\mathrm{n}^{\circ}$ 1857), sans qu'il soit possible de déterminer si cette alliance précède ou non l'entrée de Philippe à la Chambre; ajoutons que Philippe est 
sept d'entre eux n'ont aucun lien de parenté discernable avec leurs prédécesseurs 110 - même s'ils demeurent pour la plupart parfaitement intégrés au personnel de l'Hôtel royal ${ }^{111}$. C'est là la fin du quasi-monopole exercé par un groupe familial unique sur la fonction de chambellan depuis 1286.

L'avènement de Philippe $\mathrm{V}$ en juillet 1316 parachève ce phénomène. Certes, il ramène les chambellans à un effectif plus réduit : ceux-ci ne sont plus que trois ${ }^{112}$, et ils recouvrent la stabilité un temps perdue, puisque les hommes nommés en 1316 exerceront leur office durant tout le règne, voire au-delà ${ }^{113}$. Mais cette réduction drastique des effectifs va de pair avec un renouvellement complet de personnel, puisqu'un seul de ces trois chambellans, Adam Héron, l'était déjà à la mort de Louis X; encore n'était-ce que depuis quelques mois au plus ${ }^{114}$. En moins de deux ans, entre 1314 et 1316, on assiste ainsi à l'élimination totale des familles qui avaient dominé la

peut-être parent de Jeanne de Saint-Martin, première épouse d'Enguerran de Marigny, que Louis $\mathrm{X}$ mentionne dans son testament pour les services rendus à sa mère $\left(\mathrm{AN}, \mathrm{J} 404^{\mathrm{A}}\right.$, $\left.n^{\circ} 22\right)$.

110. Hugues d'Augeron, Jean de Chepoix, Adam Héron, Jean Langre, Guillaume Paumier, Gilles de Sergines et Eudes de Vaussemain.

111. Deux de ces nouveaux chambellans, Hugues d'Augeron et Eudes de Vaussemain, sont beaux-frères : Eudes est le frère de Louis de Vaussemain (Charles IV RTC, $\mathrm{n}^{\circ}$ 4530, et Philippe VI RTC, $\mathrm{n}^{\circ}$ 5295), lui-même oncle de Jean d'Augeron (le P. Anselme, Histoire généalogique..., t. II, p. 274), fils d'Hugues (Jean XXII [...], lettres communes..., $\mathrm{n}^{\circ} 319$ ) ; voir également la mention de Marie de Vaussemain, femme d'Hugues d'Augeron (BNF, lat. 9787, fol. 65v). Par ailleurs Jean de Vaussemain, sans doute frère d'Eudes, est panetier de la reine Clémence de Hongrie (BNF, fr. 7855, p. 333) et Marie de Chéu, dame de Vaussemain, mère d'Eudes (Charles IV RTC, $\mathrm{n}^{\circ}$ 4530), est l'ancienne nourrice de Louis X (AN, J 404 ${ }^{\mathrm{A}}$, $\mathrm{n}^{\circ}$ 22). De même plusieurs parents de Gilles de Sergines ont œuvré dans l'Hôtel royal : son père, Pierre (Philippe IV JT, $\mathrm{n}^{\circ} 383$ ), est chargé des plaids de la porte (ordonnance de Vincennes, 23 janvier 1286, art. 78, AN, JJ 57, fol. 6), puis nommé maître de l'Hôtel en 1288 (BNF, fr. 7855, p. 77); Geoffroi de Sergines, frère de Gilles (Les comptes [...] de la Chambre aux deniers..., p. 325, CO III, $\mathrm{n}^{\circ}$ 84), est panetier de Louis de Navarre et le reste après l'avènement de celui-ci comme roi de France (BNF, fr. 7855 , p. 120, et $\left.A N, J 404^{A}, n^{\circ} 22\right)$; Pierre de Sergines, probablement parent de Gilles, est quant à lui échanson de Louis X

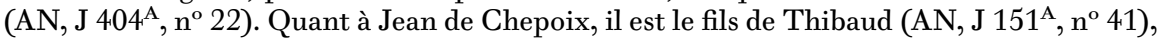
maître des arbalétriers de 1304 à 1307 (C.-V. Langlois, « Registres perdus... », p. 319 / 287, $\mathrm{n}^{\circ}$ 384; ; Philippe IV RTC, $\mathrm{n}^{\circ}$ 903) - c'est manifestement par erreur que Joseph Petit, citant une cote inexacte, a affirmé que Thibaud était maître des arbalétriers dès 1297 («Un capitaine du règne de Philippe le Bel: Thibaut de Chepoy», dans Le Moyen Âge, t. 10, 1897, p. 225-239, à la p. 227); je remercie Ghislain Brunel de m'avoir aidé à éclaircir ce point. Enfin Philippon Paumier, panetier de Clémence de Hongrie (BNF, fr. 7855, p. 333), est peut-être parent du chambellan Guillaume Paumier. Seuls Adam Héron et Jean Langre ne semblent pas avoir de parents au sein de l'Hôtel (voir toutefois note 130 pour Adam).

112. Voir annexe.

113. Voir annexe.

114. Il apparaît pour la première fois avec ce titre en juin 1316 (voir annexe). Ajoutons qu'Adam était antérieurement chambellan de Philippe de Poitiers (AN, JJ 57, fol. 25). 
Chambre durant les trente années du règne de Philippe IV - même si certains membres de ces lignées continuent à œuvrer à la cour du roi ${ }^{115}$.

Philippe V va même plus loin en 1318 : jugeant que ses prédécesseurs s'étaient montrés dispendieux et que leur entourage leur avait extorqué des avantages indus, il lance une grande opération de révocation des dons ${ }^{116}$. Et il désigne nommément «Pierre, seigneur de Chambli, Hue de Bouville et les enfans Jehan de Bouville, toute la lignee de Machaus » et quelques autres, dont Hugues d'Augeron, chambellan de Louis X, et les héritiers de Pierre IX de Chambly ${ }^{117}$, comme les cibles prioritaires de ces révocations ${ }^{118}$. Il signe là la fin de la fortune de certaines de ces familles, en particulier des Chambly, qui ne s'en relèveront pas : ceux-ci voient leurs acquisitions foncières les plus avantageuses leur échapper et sont, durant près de dix ans, la cible d'innombrables procès ${ }^{119}$.

Philippe V, non content de s'en prendre aux chambellans de ses prédécesseurs et à leurs familles, entend aussi réduire l'influence et le rôle politique qu'ont pu exercer jusqu'alors ces officiers. Certes, les attributions théoriques des chambellans n'ont manifestement pas changé sous son règne : nombre d'ordonnances de l'Hôtel émises alors en témoignent ${ }^{120}$. Mais si la plupart de ces textes ne font que rappeler des obligations et compétences

115. Ainsi Pierre II de Machau, bien qu'il ait perdu sa charge de chambellan, continue à commander des actes royaux en 1317 (Philippe V RTC, n ${ }^{\text {os }} 1109$ et 1110). De même Hugues d'Augeron, bien qu'il ne soit plus chambellan, continue, à la fin de l'année 1316 et en 1317, à appartenir à l'Hôtel en tant que chevalier (Philippe V RTC, $\mathrm{n}^{\circ} 1473$ ), gère les joyaux du roi (Comptes de l'argenterie..., p. 15) et siège à la Chambre des comptes (ibid., p. 27).

116. C.-V. Langlois, « Registres perdus... », p. 107-108 / 75-76.

117. Ceux-ci sont mentionnés comme « les enfans la dame de Neaufle ». Isabelle de Bourgogne, dame de Neaufles-Saint-Martin, est en effet veuve de Pierre IX (Philippe V RTC, $\mathrm{n}^{\circ} 1363$, et Louis X RTC, $\mathrm{n}^{\circ}$ 44).

118. Philippe V RTC, $\mathrm{n}^{\circ} 1542$.

119. Un arrêt du Parlement annule en 1321 l'essentiel des acquisitions foncières réalisées par Pierre V et Pierre VI aux dépens de la monarchie (BNF, nouv. acq. fr. 21154, $\mathrm{n}^{\circ}$ 6, édité partiellement dans C.-V. Langlois, « Registres perdus... », p. 110-111 / 78-79) ; un mandement de Charles IV vient compléter cette décision en annulant des concessions faites aux diverses branches de la famille de Chambly ( $\mathrm{AN}, \mathrm{J} 1024, \mathrm{n}^{\circ}$ 51, édité d'après une version partielle dans Ordonnances des roys de France..., t. I, p. 762-766 n). À ces procédures s'ajoutent de nombreux procès de succession, principalement entre Pierre VII, la dame de Neaufles, veuve de Pierre IX, et la comtesse de Sancerre, seconde épouse de Pierre V, procès compliqués encore par les transformations du patrimoine familial qu'entraînent les restitutions faites au roi (voir notamment Boutaric, $\mathrm{n}^{\text {os }} 6086,6426,7454,7707,7800$ et 7936 ; Charles IV RTC, $\mathrm{n}^{\circ}$ 3892, et Philippe VI RTC, $\mathrm{n}^{\circ}$ 1593). Charles IV finit par éteindre les procédures contre les Chambly en janvier 1325 (Charles IV RTC, $\mathrm{n}^{\circ}$ 5038).

120. Il est vrai que les ordonnances décrivant le rôle des chambellans sont rares avant le règne de Philippe $\mathrm{V}$; toutefois bien des indices attestent que ces ordonnances ne font que rappeler un état de fait antérieur. Ainsi en est-il des obligations consistant à veiller aux pieds du souverain (voir note 16 et texte correspondant) ou à conserver le sceau du secret (voir note 26). 
anciennes, leur précision et leur multiplication en quelques années manifestent une nette volonté de définir l'office de chambellan ${ }^{121}$. Désormais, les pouvoirs de ces derniers sont clairement fixés, et par là même clairement limités. Une ordonnance de juillet 1316 est explicite sur ce point : elle confie aux chambellans le sceau du secret, mais elle dresse la liste des actes qu'ils ne pourront en sceller ${ }^{122}$. Par ailleurs, les ordonnances de Philippe V renvoient avec insistance les chambellans à leurs compétences originelles, strictement domestiques. Même en tant que porteurs du sceau du secret, ils apparaissent comme de simples exécutants : s'ils doivent sceller les requêtes avant qu'elles ne soient transmises à la chancellerie, à aucun moment il n'est prévu qu'ils en contrôlent le contenu ${ }^{123}$. Ils sont ainsi cantonnés dans la dimension la plus domestique de leurs fonctions, fût-elle la plus prestigieuse sur le plan symbolique ${ }^{124}$.

La politique qui semble se dessiner dans ces ordonnances se concrétise dans la faible influence qu'exercent sur Philippe V ses chambellans. Ainsi, aucun d'entre eux ne semble avoir siégé au Conseil ${ }^{125}$. Certes, ils conservent la capacité de conseiller le roi : ils sont par exemple convoqués en 1319 à une assemblée pour délibérer sur la croisade ${ }^{126}$. Ils continuent

121. Quatre ordonnances évoquent en particulier les attributions des chambellans : celle de Saint-Germain-en-Laye, de juillet 1316 (AN, JJ 57, fol. 42, art. 10), celle du Bois de Vincennes de décembre 1316 (ibid., fol. 57-v, art. 3), celle de Lorris du 17 novembre 1317 (ibid., fol. 74-v, art. 3) et celle de Bourges du 16 novembre 1318 (Ordonnances des roys de France..., t. I, p. 670 et 673, art. 3, 4 et 27). Certes, la présence de trois de ces textes dans le même recueil pourrait laisser penser que leur accumulation, au début du règne de Philippe $\mathrm{V}$, est uniquement liée à la richesse des sources pour cette période. En réalité, des ordonnances de l'Hôtel de la fin du règne de Philippe IV et de celui de Louis X nous sont aussi parvenues, mais elles ne font que de brèves allusions aux chambellans ou se contentent de mentionner leurs droits et gages à l'Hôtel (ordonnance de 1306-1307, art. 3, AN, JJ 57, fol. 49 ; ordonnance de l'union des hôtels de 1315 , art. 15 , BNF, fr. 7855 , p. 257 ; pour la date de ces textes, voir respectivement note 10 et O. Canteaut, Gouvernement..., t. I, p. 113, n. 449).

122. Ordonnance de Saint-Germain-en-Laye, art. 10, AN, JJ 57, fol. 42v : « duquel [petit seel] il ne pourront sceller ne signer lettres de justice, ne de office, ne de benefice, ne de nulle autre chose ».

123. Ordonnance de Bourges, art. 4, dans Ordonnances des roys de France..., t. I, p. 670.

124. À la fin du XII ${ }^{\mathrm{e}}$ siècle, les grands officiers de la Couronne, et en particulier le sénéchal, avaient déjà connu un tel repli autour de leurs tâches les plus honorifiques, à savoir celles qui touchent au service domestique du roi (É. Bournazel, Le gouvernement..., p. 124125).

125. Seule exception, le chambellan de France Mathieu de Trie siégea au Conseil durant la régence de Philippe de Poitiers, à compter de juillet 1316 (ordonnance de Saint-Germain, art. 1, AN, JJ 57, fol. 40v) ; mais, passé cette date, Mathieu semble disparaittre de l'entourage royal, si l'on excepte sa convocation, avec bien d'autres nobles, à l'ost à la fin de l'année 1317 (Philippe V RTC, ${ }^{\text {os }} 1518$ et 1519). Pour une liste des participants au Conseil du roi sous Philippe V, voir O. Canteaut, Gouvernement..., t. I, p. 22-31.

126. Philippe V RTC, $\mathrm{n}^{\circ} 2654$ bis. Les trois chambellans n'apparaissent qu'en $29^{\mathrm{e}}$ position dans la liste hiérarchique énumérant ces convocations. 
également à commander des actes de donation, mais leur latitude en la matière semble restreinte ${ }^{127}$ : les libéralités qu'ils commandent sont non seulement moins nombreuses, mais aussi plus modestes que celles ordonnées par leurs prédécesseurs ${ }^{128}$. De manière générale, les chambellans ne semblent pas bénéficier, de la part de Philippe $\mathrm{V}$, de la même confiance que sous Philippe IV. À preuve, ils ne reçoivent plus la moindre commission, attachés qu'ils sont à leurs obligations domestiques. Leur influence à l'Hôtel même paraît très limitée : les finances de l'Hôtel et de la Chambre leur ont échappé au profit d'officiers indépendants ${ }^{129}$, et surtout ils ne peuvent s'appuyer sur aucun réseau de parents ni de clients au sein de l'Hôtel ${ }^{130}$. Seul le chambellan de France, le vicomte de Melun, fait exception par ses liens avec le bouteiller Henri de Sully ${ }^{131}$; mais il est avant tout

127. L'ordonnance de Saint-Germain-en-Laye, en 1316, semble exclure des compétences des chambellans les donations d'importance, qu'il s'agisse de les sceller du petit sceau ou d'en commander la rédaction auprès d'un notaire ( $\mathrm{AN}, \mathrm{JJ} 57$, fol. $42 \mathrm{v}$, art. 10). Les ordonnances de Pontoise et de Bourges, en 1318, réservent quant à elles le commandement des lettres de don au Conseil et à ses membres (Ordonnances des roys de France..., t. I, p. 657658 , art. 1, et p. 673, art. 27). Ces différentes prescriptions ont toutefois été suivies de peu d'effet (O. Canteaut, Gouvernement..., t. III, p. 601-603).

128. Nous avons trouvé la trace de 55 actes commandés par le chambellan de France et par les trois chambellans du roi sous Philippe V. Ces actes représentent moins d'un pour cent des 6400 lettres de Philippe $\mathrm{V}$ parvenues jusqu'à nous, alors que les actes commandés par des chambellans représentent environ 2,5\% des actes émis durant les dix-huit derniers mois du règne de Philippe IV ou encore sous Louis X. Cet écart est encore plus grand si l'on ne prend en considération que les actes transcrits dans les registres de chartes de la chancellerie - qui sont établis selon des principes uniformes depuis les années 1310. Les chambellans de Philippe V commandent ainsi seulement $1 \%$ des chartes qui y sont enregistrées, alors que leurs prédécesseurs étaient à l'origine de plus de $5 \%$ des chartes transcrites à la fin du règne de Philippe IV, et même de $6 \%$ d'entre elles durant le règne de Louis $\mathrm{X}$. De fait, durant plus d'un an et demi, les chambellans de Philippe V n'ont commandé aucune charte royale, les premières qui soient émises sur leur ordre datant de mars 1318 (Philippe V RTC, $\mathrm{n}^{\text {os }} 1708$ et 1736). En revanche, ils ont ordonné l'expédition de nombre de mesures temporaires : 21 des actes qu'ils ont commandés sont des dons à vie ou à volonté (Philippe V RTC, $\mathrm{n}^{\text {os }} 917$, $1145,1178 \ldots$..) ou des nominations à des offices domaniaux modestes (Philippe V RTC, $\left.\mathrm{n}^{\text {os }} 1241,1255,1261 \ldots\right)$, tous conservés dans les registres pour lettres de cire blanche qui ont été tenus par la chancellerie entre 1317 et 1320 (sur ces registres, voir O. Canteaut, Gouvernement..., t. II, p. 214); et 10 autres lettres émises sur leur ordre touchent à la justice criminelle et sont consignées dans les registres du Parlement (AN, $\mathrm{X}^{2 \mathrm{~A}} 2$, fol. 2, 6, 19, 104, 108v, $113,115 \mathrm{v}, 128 \mathrm{v}$ et 193$)$.

129. Les maîtres de la Chambre aux deniers et l'argentier nommés en juillet 1316 n'entretiennent aucun lien avec les chambellans (ordonnance de Saint-Germain-en-Laye, art. 12 et 13, AN, JJ 57, fol. 42v).

130. Signalons tout au plus la présence à l'Hôtel de Robin Hairon, valet en 1313 (Les comptes [...] de la Chambre aux deniers..., p. 872, appendice, $\mathrm{n}^{\circ}$ 102), et de Jean Héron, souffleur de cuisine en 1315 (BNF, fr. 7855, p. 333); nous ignorons au demeurant si ces hommes sont parents d'Adam Héron.

131. Jean est cousin germain d'Henri de Sully, par sa mère Jeanne de Sully (le P. Anselme, Histoire généalogique..., t. II, p. 857). Par l'intermédiaire des Sully, Jean est également apparenté aux Bouville (Philippe V RTC, $n^{\circ}$ 3453), puisque Jean de Bouville a 
un relais de ce dernier à la Chambre ${ }^{132}$ et ne pèse guère dans l'entourage royal ${ }^{133}$. Pareil isolement des chambellans au sein de l'Hôtel ne peut qu'étonner dans la mesure où celui-ci continue, comme sous Philippe IV, à être innervé par de puissants réseaux familiaux ${ }^{134}$. Conséquence enfin de leur faible poids politique, les chambellans de Philippe $\mathrm{V}$ ne bénéficient pas des mêmes avantages que leurs prédécesseurs. Ils sont certes récompensés par quelques dons - vingt-deux livres parisis de rente perpétuelle pour Adam Héron ${ }^{135}$, quatre cents livres tournois de rente viagère et cinquante charretées de bois pour le Borgne de Séry ${ }^{136}$, l'abandon de treize livres parisis dues au roi et une autorisation de création de marché pour Jean de Melun ${ }^{137}$-, mais de telles sommes ne sont nullement comparables aux dons qui ont fait la fortune des Chambly ou d'Enguerran de Marigny.

Philippe V semble donc avoir fait le choix volontaire de retenir pour chambellans de parfaits inconnus et il n'a rien fait ensuite pour les tirer

épousé une cousine maternelle d'Henri de Sully (É. Richemond, Recherches généalogiques..., planche entre les p. 96 et 97 ).

132. Sur le réseau familial d'Henri de Sully, qui innerve l'ensemble du gouvernement royal, voir O. Canteaut, Gouvernement..., t. II, p. 456.

133. Jean est quasi absent de la documentation durant le règne de Philippe $\mathrm{V}$ : alors qu'il est nommé chambellan de France entre la fin de l'année 1317 et août 1320 (voir annexe), il ne commande que trois actes royaux entre 1317 et 1321 (AN, $\mathrm{X}^{2 \mathrm{~A}} 2$, fol. 104 et $115 \mathrm{v}$, et BNF, fr. 2755, fol. 401) et se contente de participer à l'ost de Flandre en 1318 (BNF, fr. 9501, fol. 93, et Albert Pagart d'Hermensart, « Lettres de Philippe V aux échevins de Saint-Omer pendant la révolte de la noblesse d'Artois contre la comtesse Mahaut [1317-1319] », dans Bulletin historique et philologique du Comité des travaux historiques et scientifiques de France, 1894, p. 576-588, aux p. 583-584) et, l'année suivante, d'être convoqué, en $25^{\mathrm{e}}$ position, à une assemblée sur la croisade (Philippe V RTC, $\mathrm{n}^{\circ}$ 2654 bis). Il faut attendre 1326 pour le voir siéger au Conseil (Charles IV RTC, $\mathrm{n}^{\circ}$ 4785), puis la fin du règne de Philippe VI pour qu'il joue un rôle politique notable (Raymond Cazelles, La société politique et la crise de la royauté sous Philippe de Valois, Paris, 1958 [Bibliothèque elzévirienne, études et documents], p. 179, n. 6 , et p. 339, n. 7).

134. Outre le cas d'Henri de Sully (voir note 132), citons, parmi de nombreux exemples, celui de la famille d'Arrabloy. Pierre d'Arrabloy est ainsi chancelier de France de l'avènement de Philippe V au mois de janvier 1317 (O. Canteaut, Gouvernement..., t. III, p. 642); dans le même temps son père, Jean, siège aux requêtes de l'Hôtel, où il est remplacé, avant janvier 1320, par son fils et homonyme (ibid., t. II, p. 484-485); enfin Guillaume d'Arrabloy, fils de Jean le vieux, est retenu comme clerc et familier du roi en 1317 (Philippe V RTC, $\mathrm{n}^{\circ}$ 2321). Sur les liens familiaux qui unissent les officiers de l'Hôtel, voir O. Canteaut, Gouvernement..., t. II, p. 463-466.

135. Philippe V RTC, $\mathrm{n}^{\circ} 2046$.

136. Charles IV RTC, $n^{\circ} 3897$, et BNF, fr. 2755 , fol. 375. Gui de Séry semble toutefois avoir bénéficié d'un troisième don, qui ne nous est plus connu que par une analyse et dont la valeur demeure inconnue (AN, PP 105, fol. 499v, et Bibl. mun. Rouen, Leber 5870 [Menant], t. V, fol. 154v).

137. BNF, Clairambault $177, \mathrm{n}^{\circ} 57$, et Souverains et princes de France, huit siècles de l'histoire de France : lettres et manuscrits autographes, documents historiques (catalogue de vente, étude Piasa, 27 mars 2007), Paris, 2007, $\mathrm{n}^{\circ}$ 5. Ajoutons que le testament de la reine établi en 1319 prévoit d'accorder un legs de 500 livres à Jean (AN, J 404 ${ }^{\mathrm{A}}, \mathrm{n}^{\mathrm{o}} 23$ ). 
de leur obscurité. Ajoutons qu'il réserve un sort similaire aux maîtres de l'Hôtel. Philippe IV puis Louis X, qui avait multiplié les offices de maître ${ }^{138}$, y avaient nommé des chevaliers d'un niveau social proche de celui des chambellans ${ }^{139}$, auxquels ils étaient parfois apparentés ${ }^{140}$, ainsi que des financiers influents de la monarchie ${ }^{141}$. Or, à compter de 1317, ces

138. Il est entouré en 1315 de dix maîtres de l'Hôtel (BNF, fr. 7855, p. 138), alors que ceux-ci n'étaient sans doute que quatre à la fin du règne de Philippe IV : Martin des Essarts (Philippe IV RTC, $\mathrm{n}^{\circ}$ 2163), Guillaume de Flavacourt (Philippe IV RTC, $\mathrm{n}^{\circ}$ 1404), Baudouin de Rouy (Philippe IV RTC, $\mathrm{n}^{\circ}$ 1993) et Jean de Villepreux (Regestum Clementis papae V..., t. VII, $\mathrm{n}^{\circ}$ 7675).

139. Il s'agit avant tout de petits nobles du vieux domaine capétien, tels que Jean de Beaumont, seigneur de Sainte-Geneviève-des-Bois (Loiret, cant. Châtillon-Coligny) et souverain maître de l'Hôtel sans discontinuer entre 1315 et 1337 (BNF, fr. 7855, p. 138; le P. Anselme, Histoire généalogique..., t. VIII, p. 311); ou encore Jean de Villepreux, maître de l'Hôtel du roi en 1311 et 1312 (AN, J 389, $\mathrm{n}^{\circ}$ 6, et Regestum Clementis papae V..., t. VII, $\mathrm{n}^{\circ}$ 7675), puis maître de l'Hôtel de la reine en 1315 (BNF, fr. 7855, p. 138), et qui possède un manoir à Villepreux (Yvelines, cant. Saint-Nom-la-Bretèche ; Jean XXII [...], lettres communes..., $\mathrm{n}^{\circ}$ 15681). Autre indice de la similitude du recrutement social des chambellans et des maîtres de l'Hôtel : certains individus ont pu occuper ces deux fonctions successivement. Ainsi Mathieu de Trie, avant d'être nommé chambellan de France par Philippe IV, était grand maître de l'Hôtel (Comptes royaux, 1285-1314..., $\mathrm{n}^{\circ}$ 5983; sur la qualification exacte de sa fonction, voir AN, JJ 57, fol. 57v); de même, Gui de Séry, chambellan de Philippe V et de Charles IV, finira sa carrière comme souverain maître de l'Hôtel de Philippe VI (R. Fawtier, «Un compte de menues dépenses de l'Hôtel du roi Philippe VI de Valois pour le premier semestre de l'année 1337 », dans Bulletin philologique et historique [jusqu'à 1715] du Comité des travaux historiques et scientifiques, p. 183-239, au $\left.\mathrm{n}^{\circ} 154\right)$.

140. Ainsi en est-il de Guillaume de Flavacourt, maître de l'Hôtel à la fin du règne de Philippe IV et cousin d'Enguerran de Marigny (voir note 99).

141. Plusieurs maîtres de l'Hôtel cumulent cette charge avec celle de maître de la Chambre aux deniers et de trésorier, ainsi qu'avec divers offices de finance très lucratifs. Ainsi Renaud de Rouy, fournisseur récurrent sous Philippe IV des garnisons royales, en particulier pour l'ost (Inventaire d'anciens comptes..., $\mathrm{n}^{\text {os }}$ 52, 2502 et 2619), maître de l'Hôtel à compter de mars 1305 (BNF, Clairambault 48, $\mathrm{n}^{\circ} 6$ ), probablement maître de la Chambre aux deniers à partir du début de l'année 1307 (Les comptes [...] de la Chambre aux deniers..., p. Xxx), et enfin trésorier du roi quelques mois plus tard en mai 1307 (BNF, Clairambault $28, n^{\circ} 121$ ) ; il conserve l'ensemble de ces charges jusqu'à sa mort à la fin de l'année 1311 ou au début de l'année 1312 (Inventaire d'anciens comptes..., $\mathrm{n}^{\text {os }} 1986$ et 2502). Son frère Baudouin remplit les mêmes fonctions, en particulier à partir de la mort de Renaud : fournisseur de garnisons depuis 1307 (Inventaire d'anciens comptes..., $\mathrm{n}^{\circ}$ 2516), il devient maître de l'Hôtel en 1310 (Philippe IV RTC, $\mathrm{n}^{\circ}$ 1131), succède à son frère comme maître de la Chambre aux deniers (Les comptes [...] de la Chambre aux deniers..., p. xxxI) et est enfin nommé trésorier à compter de 1313 (AN, JJ 57, fol. 19); il cumule au moins les fonctions de maître de l'Hôtel, de trésorier et de maitre des garnisons jusqu'à la fin du règne de Louis X (BNF, fr. 25993, $\mathrm{n}^{\circ}$ 220, et André Artonne, Le mouvement de 1314 et les chartes provinciales de 1315, Paris, 1912 [Université de Paris, Bibliothèque de la faculté des lettres, 29], p. j. no 20, p. 194). Martin des Essarts accomplit une carrière similaire à celle des frères de Rouy : il fournit des garnisons royales en 1311 (Inventaire d'anciens comptes..., $\mathrm{n}^{\circ}$ 2519), est maître de l'Hôtel de 1313 ou 1314 à 1316 (Comptes royaux, 1285-1314..., $\mathrm{n}^{\text {os }} 27691$ et 27786, et Philippe IV RTC, $\mathrm{n}^{\circ} 2163$; AN, JJ 57, fol. 67v) et cumule sous Louis X cette fonction avec celles de trésorier et de maître des comptes (Clovis Brunel, «Documents sur le Pontieu 
derniers ne sont plus appelés à de telles fonctions, à une exception près ${ }^{142}$. Les maîtres de l'Hôtel perdent alors toute compétence financière ${ }^{143}$ et aucun d'entre eux ne semble jouir d'une quelconque influence sous Philippe $\mathrm{V}$, au point que l'on peine à établir la liste de ceux qui occupèrent cette charge durant ce règne ${ }^{144}$.

Cette perte d'influence du personnel gouvernant l'Hôtel semble être la contrepartie du développement des institutions de la monarchie. En effet, le règne de Philippe $\mathrm{V}$ constitue un moment de cristallisation institutionnelle pour l'appareil d'État capétien. Ainsi est-ce un moment décisif dans l'histoire de la Chambre des comptes, dont les maîtres exercent une grande

conservés dans la collection de l'Ancient correspondence au Public Record Office de Londres [1278-1337] », dans Bulletin philologique et historique [jusqu'à 1715] du Comité des travaux historiques et scientifiques, 1917, p. 231-277, $\mathrm{n}^{\circ} 43$, p. 271-272, probablement daté du premier semestre de 1316, comme en témoigne la mention d'Hugues d'Augeron comme maître des comptes; voir sur ce point note 40 et texte correspondant). De son côté, Pierre Remi cumule durant le règne de Louis $\mathrm{X}$ les fonctions de maître de l'Hôtel et de maître de la Chambre aux deniers (Louis X RTC, $\mathrm{n}^{\circ}$ 99, et Comptes du Trésor..., $\mathrm{n}^{\circ}$ 849), auxquelles s'ajoute la charge de trésorier entre janvier et juin 1316 (ibid., $\mathrm{n}^{\circ}$ 792). Enfin Gencien Coquatrix, maître de l'Hôtel de Louis X (BNF, fr. 7855, p. 138), se contente de ce seul office, mais il n'en est pas moins influent : son père, Geoffroi Coquatrix, l'un des plus riches bourgeois de Paris, fut administrateur des finances royales sous Philippe IV dans de multiples circonstances (Boris Bove, Dominer la ville : prévôts des marchands et échevins parisiens de 1260 à 1350, Paris, 2004, p. 309-310), notamment comme maître des comptes entre 1304 et 1316 (J. Favier, Un conseiller..., p. 231 / 797, et Comptes du Trésor..., n ${ }^{\circ}$ 792).

142. Baudouin de Rouy demeure maître de l'Hôtel durant tout le règne de Philippe V, mais il n'est attesté dans cette fonction qu'à trois reprises, en novembre 1316 (Arch. dép. Pas-de-Calais, A 61, $\mathrm{n}^{\circ}$ 18), en août 1318 (Philippe V RTC, $\mathrm{n}^{\circ}$ 2988) et en octobre 1321 (BNF, fr. 2755, fol. 372v). Il conserve dans le même temps ses fonctions de fournisseur des garnisons de l'ost (Inventaire d'anciens comptes..., $\mathrm{n}^{\circ} 2518$ ), mais abandonne son office de trésorier dès l'arrivée au pouvoir de Philippe de Poitiers (ordonnance de Saint-Germain-enLaye de juillet 1316, art. 7, AN, JJ 57, fol. 41v). Signalons également qu'une ordonnance de décembre 1316 affirme que Martin des Essarts conserve alors sa charge de maître de l'Hôtel (AN, JJ 57, fol. 67v), mais ce titre ne lui est plus attribué par la suite.

143. L'avènement de Philippe de Poitiers entraîne notamment la nomination de nouveaux maitres à la Chambre aux deniers (AN, JJ 57, fol. 42v, art. 13), en remplacement du maître de l'Hôtel Pierre Remi. Désormais, le personnel de la Chambre aux deniers n'entretient plus de liens avec les maîtres de l'Hôtel.

144. Six maîtres nous sont connus. À Jean de Beaumont, souverain maître de l'Hôtel (voir note 139), à Baudouin de Rouy et à Martin des Essarts (voir note 142), s'ajoutent: Guillebaud d'Échilleuses, attesté entre décembre 1316 et janvier 1318 (Philippe V RTC, $\mathrm{n}^{\text {os }} 1401$ et 1671); Robert de Sermizelles, maître de l'Hôtel de Louis X (BNF, fr. 7855, p. 138), puis de Philippe V en 1319 (Arch. dép. Côte-d'Or, B 383, cité d'après ibid., B 12016 [Peincedé, t. XXIII], p. 622) sans qu'il soit possible de déterminer s'il exerce sans solution de continuité sous Louis X et Philippe V ; et enfin Pierre Pouvreau, qui a occupé cette fonction à une date inconnue (Charles IV JT, $\mathrm{n}^{\circ}$ 5225). Selon une chronique du Xvi ${ }^{\mathrm{e}}$ siècle, il faudrait ajouter à cette liste Jean d'Égreville (Guillaume Paradin, Chronique de Savoye, $3^{\mathrm{e}}$ éd., [Genève], 1602, livre II, chap. 119, p. 207); cette indication est toutefois sujette à caution. 
influence sur le gouvernement du royaume ${ }^{145}$. Dans le même temps, le Conseil du roi tend à s'institutionnaliser et conquiert même un début d'autonomie par rapport à la personne royale ${ }^{146}$. Il n'est pas jusqu'aux requêtes de l'Hôtel qui ne connaissent un phénomène similaire, s'érigeant dans les années 1320 en un service administratif cohérent et autonome ${ }^{147}$. Le gouvernement du royaume tend peu à peu à entrer dans des cadres institutionnels définis - même si le roi continue à pouvoir solliciter le conseil informel de qui bon lui semble ${ }^{148}$.

Au gré d'une telle évolution, l'Hôtel ne se voit pas exclu du gouvernement, mais il abrite désormais deux types d'officiers. Les premiers sont à la tête de services administratifs largement autonomes, qu'ils soient hébergés à l'Hôtel et suivent le roi, ou qu'ils soient sédentarisés à Paris. Tel est le cas des maîtres des requêtes de l'Hôtel, mais aussi de grands officiers de la Couronne comme le chancelier, le connétable ou encore le bouteiller de France : ainsi que l'a montré Raymond Cazelles, tous ont su s'intégrer à la monarchie administrative du début du $\mathrm{XIV}^{\mathrm{e}}$ siècle ${ }^{149}$. Le reste des officiers de l'Hôtel conservent des fonctions purement domestiques ${ }^{150}$, et Philippe $\mathrm{V}$ relègue clairement les chambellans - et les maîtres de l'Hôtel-dans cette catégorie ${ }^{151}$.

$$
* *
$$

145. L'ordonnance du Vivier-en-Brie, édictée en janvier 1320, est souvent considérée comme le texte fondateur de la Chambre (É. Lalou, «La Chambre des comptes », dans Lexikon des Mittelalters, t. II, Munich, 1983, col. 1673-1675, à la col. 1674). Sur le rôle des maîtres des comptes dans le gouvernement royal sous Philippe V, voir O. Canteaut, Gouvernement..., t. III, p. 614-636.

146. Ibid., t. III, p. 605-607.

147. En témoigne en particulier l'apparition de la mention de commandement «in requistis Hospitii » qui est attestée au bas des actes royaux à compter de 1322 (BNF, fr. $6539, \mathrm{n}^{\circ} 8$; pour ses variantes, voir O. Canteaut, Gouvernement..., t. I, p. 58, n. 180) et sa généralisation progressive au détriment des mentions de commandement individuelles des maîtres des requêtes. Cette autonomie croissante du service des requêtes se traduit également par la relative rareté des liens qui unissent les maîtres des requêtes au reste du personnel de l'Hôtel (ibid., t. II, p. 461 et 464).

148. O. Canteaut, « Le roi de France... », p. 172-174

149. R. Cazelles, «Un problème d'intégration... », p. 184-188.

150. Cette division de l'Hôtel entre sphère domestique et sphère étatique se surimpose ainsi au partage opéré par É. Lalou entre service du commun et service de la personne royale («Chancellerie et hôtel... », p. 19-20) : cette dernière distinction ne paraît valide que pour les officiers domestiques de l'Hôtel.

151. Le mouvement de balancier qui semble ainsi exister entre renforcement institutionnel de l'appareil étatique d'une part et influence politique des chambellans d'autre part, se constatera de nouveau, dans la direction contraire, à la fin du règne de Charles $\mathrm{V}$ : se dessine alors un affaiblissement des institutions royales, en particulier du Conseil, auquel répond un rôle accru de la Chambre, et notamment du chambellan Bureau de La Rivière (R. Cazelles, Société politique..., p. 545). 
Certes, la politique qui consiste à évincer les dynasties de chambellans aboutit en fin de compte à un demi-échec. Dès l'avènement de Charles IV en 1322, on assiste au retour en grâce d'Hugues III de Bouville, qui regagne la Chambre ${ }^{152}$; Pierre II de Machau connaît également une nouvelle carrière, même s'il ne retrouve pas sa charge de chambellan ${ }^{153}$. Dans le même temps, le nouveau roi, après avoir à son tour prononcé des mesures de confiscation à l'encontre des chambellans de Philippe IV et de Louis $\mathrm{X}^{154}$, se montre bientôt clément ${ }^{155}$. Mais surtout les chambellans nommés en 1322 ont de nouveau partie liée aux réseaux familiaux qui unissent les membres de l'Hôtel entre eux - même s'ils ne reconstituent pas de véritables dynasties ${ }^{156}$. Anseau de Chantemelle, un des nouveaux chambellans du roi ${ }^{157}$, a par exemple pour frère l'un des échansons du roi ${ }^{158}$ et pour oncle Guillaume de Flavacourt ${ }^{159}$, ancien maître de l'Hôtel et cousin d'Enguerran de Marigny ${ }^{160}$. Cette situation perdure sous Philippe VI, pardelà quelques changements de personnel ${ }^{161}$.

152. Voir annexe.

153. Il devient maître des eaux et forêts en septembre 1325 (Inventaire d'anciens comptes..., $\mathrm{n}^{\mathrm{o}}$ 2256) et commande à ce titre plusieurs actes royaux (Charles IV RTC, $\mathrm{n}^{\text {os }} 4759$ et 4887). Il conserve cet office sous Philippe VI (J. Viard, « L'Hôtel de Philippe VI de Valois », dans Bibliothèque de l'École des chartes, t. 55, 1894, p. 465-487 et 598-626, à la p. 610).

154. Les 5 et 18 avril 1322, Charles IV prend de nouvelles mesures à l'encontre des Chambly et des Machau (AN, J 1024, ${ }^{\circ}$ 51, édité d'après une version partielle dans Ordonnances des roys de France..., t. I, p. 762-766 n.; Joseph Petit, Michel Gavrilovitch, Lucien Maury et D.-A. Teodoru, Essai de restitution des plus anciens mémoriaux de la Chambre des comptes, Paris, 1899 [Université de Paris, Bibliothèque de la faculté des lettres, 7], $\mathrm{n}^{\circ}$ XVIII, p. 160-161).

155. En janvier 1323, il restitue à Mathieu de Trie des biens que lui avait donnés Philippe IV et qui lui avaient été confisqués depuis (Charles IV RTC, $\mathrm{n}^{\circ}$ 4058). Puis, le $1^{\text {er }}$ février 1323, il abandonne à Hugues d'Augeron les revenus que celui-ci a perçus sur une maison donnée par Louis $\mathrm{X}$, mais confisquée depuis (Charles IV RTC, $\mathrm{n}^{\circ}$ 3924), avant de lui accorder dans les jours qui suivent 5600 l.t. de dédommagement (AN, J 396, $\mathrm{n}^{\circ} 17$ bis). Enfin, en janvier 1325, il renonce à toute nouvelle confiscation contre les Chambly (Charles IV RTC, $\mathrm{n}^{\circ}$ 5038).

156. Les chambellans de Charles IV n'entretiennent aucun lien de parenté direct entre eux.

157. Voir annexe.

158. BNF, fr. 7855 , p. 272 et 305. Sur leur lien de parenté, ibid., p. 154.

159. Charles IV RTC, $\mathrm{n}^{\text {os }} 3733$ et 3754; voir également BNF, lat. 5462, p. 56.

160. Voir note 99.

161. La famille d'Andrezel en constitue sans doute le cas emblématique. Jean d'Andrezel est chambellan de Philippe de Valois en 1327 (abbé Jean Lebeuf, Mémoires concernant l'histoire civile et ecclésiastique d'Auxerre..., continués par Ambroise Challe et Maximilien Quantin, Auxerre et Paris, 1848-1855, 4 vol., t. IV, $\mathrm{n}^{\circ}$ 278), puis, après l'avènement de son maître, chambellan du roi jusqu'en 1345 (Actes du parlement de Paris, deuxième série, de l'an 1328 à l'an 1350 : jugés [lettres, arrêts, jugés], par Henri Furgeot, Paris, 1920-1975, 3 vol. [Archives nationales, Inventaires et documents], $\mathrm{n}^{\circ}$ 6745). Sans doute est-il le fils d'Aubert d'Andrezel, lui-même chambellan de Charles de Valois en 1315 (AN, J 377, no 22 ${ }^{1}$ ). Quant au fils de Jean, Jean d'Andrezel le jeune, il est chambellan du duc de Normandie à partir de 
En revanche, le succès institutionnel de la politique de Philippe $\mathrm{V}$ est indubitable. Charles IV continue, comme son frère, à ne confier que peu de missions à ses chambellans ${ }^{162}$, à ne leur laisser commander que peu de lettres royaux ${ }^{163}$, à ne leur accorder que peu de libéralités ${ }^{164}$, et, pas plus que Philippe V, il ne leur confère l'honneur d'accomplir son exécution testamentaire ${ }^{165}$. L'influence politique des chambellans semble durablement

1347 (BNF, P. O. 59, dossier 1268 Andresel, $\mathrm{n}^{\circ}$ 6), puis chambellan du roi après l'avènement de Jean le Bon (ibid., $\mathrm{n}^{\circ} 13$ ) et le demeure encore sous Charles $\mathrm{V}$ jusqu'en 1366 au moins (AN, J 158, Melun II, $\mathrm{n}^{\circ}$ 25-26). Ajoutons que Jean le jeune a épousé la petite-fille de Jean d'Arrabloy le jeune (Actes du parlement..., $\mathrm{n}^{\circ}$ 6670). Or Jean d'Arrabloy, lui-même maître de l'Hôtel de Philippe VI (Philippe VI JT, n ${ }^{\text {os }} 614$ et 615), est apparenté à de nombreux officiers de l'Hôtel des derniers Capétiens (voir note 134). De même, à la fin de son règne, Philippe VI choisit pour chambellan Louis de Beaumont (Philippe VI RTC, $n^{\circ}$ 2564). Or celui-ci est étroitement lié au personnel de l'Hôtel royal : il est le fils du souverain maître de l'Hôtel Jean de Beaumont (le P. Anselme, Histoire généalogique..., t. VIII, p. 312); il épouse dès 1339 la veuve de Pierre II de Machau (Philippe VI RTC, $n^{\circ}$ 3950); et sa fille Marguerite épouse Guillaume II Flote, chambellan du roi (le P. Anselme, Histoire généalogique..., t. VIII, p. 312 - la qualité de chambellan de Guillaume II n'est cependant confirmée par aucune autre source), fils de l'amiral de France Pierre Flote et petit-fils et arrière-petit-fils des chanceliers Guillaume I et Pierre Flote (ibid., t. VI, p. 275-276).

162. Anseau de Chantemelle effectue deux missions durant le règne de Charles IV : il est gardien de l'évêque de Beauvais en 1323 (Boutaric, $n^{\circ}$ 7144) et se rend en Gascogne en 1326 (BNF, Clairambault 212, $\mathrm{n}^{\circ}$ 13). Hugues de Bouville accomplit quant à lui un voyage auprès d'Édouard II en 1323 (Charles IV JT, n ${ }^{\circ} 4357$, et Foedera ... [cité note 47], t. II, p. 531); il participe également à l'échiquier de Normandie de la Saint-Michel 1323 (Charles IV JT, $\mathrm{n}^{\circ}$ 5120); il reçoit enfin un mémoire rédigé par les enquêteurs-réformateurs envoyés en Navarre en 1324, sans qu'il soit possible de connaître son rôle dans cette affaire (AN, J 619, no 35). Quant à Gui de Ribécourt et à Gui de La Roche, leur seule intervention hors de la Chambre concerne, en 1324, une procédure judiciaire (Charles IV RTC, $\mathrm{n}^{\circ}$ 4264). Enfin, Gui de Séry n'effectue aucune mission sous le règne de Charles IV.

163. Hugues III de Bouville en commande seize (Charles IV RTC, $\mathrm{n}^{\circ} 3874,5252 \ldots$..), Gui de Ribécourt onze (BNF, fr. 2755, fol. 429v, 480v...), Anseau de Chantemelle neuf (BNF, fr. 2755, fol. 423; Charles IV RTC, $\left.\mathrm{n}^{\circ} 4663 \ldots\right)$, Gui de La Roche trois (AN, $\mathrm{X}^{2 \mathrm{~A}} 2$ 2, fol. 92v; BNF, fr. 2755, fol. 474v; Charles IV RTC, $\mathrm{n}^{\circ}$ 4666) et Gui de Séry aucune. Au total, comme sous Philippe V, ils sont à l'origine de moins d'1 \% des actes de Charles IV qui soient conservés et, à l'exception d'Hugues de Bouville, ils commandent en très large majorité des lettres temporaires, scellées de cire blanche, au point qu'aucun chambellan n'ordonne l'expédition d'une charte royale entre décembre 1322 et mars 1325 (Charles IV RTC, ${ }^{\text {os }} 3728$ et 4394). Pour une comparaison avec les règnes antérieurs, voir note 128.

164. Ce sont Gui de Ribécourt et Anseau de Chantemelle qui reçoivent les dons les plus importants : un droit de pasnage (Charles IV JT, $\mathrm{n}^{\circ}$ 4249), 800 l. par. en argent (ibid., $\mathrm{n}^{\circ}$ 5638), l'abandon de $160 \mathrm{l}$. par. dues au roi (ibid., $\mathrm{n}^{\circ}$ 9053) et enfin une maison à Paris (Charles IV RTC, $\mathrm{n}^{\circ}$ 4507) pour Gui; 1000 l. t. (Charles IV JT, $\mathrm{n}^{\circ}$ 3341), un droit de panage (ibid., $\mathrm{n}^{\mathrm{o}}$ 4254) et deux maisons à Paris (Charles IV RTC, $\mathrm{n}^{\text {os }} 4875$ et 4876) pour Anseau. Gui de La Roche reçoit lui aussi une maison à Paris (Charles IV RTC, $\mathrm{n}^{\circ}$ 5338); Hugues III de Bouville touche de son côté un don de 1000 l. t. (Charles IV JT, $n^{\circ}$ 9615). Enfin, Gui de Séry ne bénéficie d'aucun don de Charles IV mais se voit confirmer un don de Philippe V (Charles IV RTC, $\left.\mathrm{n}^{\circ} 3897\right)$.

165. AN, J 404 ${ }^{\mathrm{A}}, \mathrm{n}^{\text {os }} 26$ et 27 (testament et codicille de Philippe V) et $\mathrm{n}^{\text {os }} 29$ et 29 bis (testament et codicille de Charles IV). Ces testaments rompent une tradition remontant à 
réduite : il faut attendre Robert de Lorris sous Jean II pour qu'un chambellan ait de nouveau l'oreille du roi ${ }^{166}$. De façon concomitante, toute possibilité pour la Chambre de se transformer en un service stable, participant au gouvernement et s'insérant pleinement dans les rouages de la monarchie, est écartée durant le règne de Philippe $\mathrm{V}$, alors même que l'hypothèse semblait s'en dessiner sous Philippe IV. Même le développement éphémère d'une petite chancellerie autour du sceau du secret de Philippe VI, dans les années $1330^{167}$, ne semble pas avoir été l'occasion d'une nouvelle heure de gloire pour les chambellans 168 : aucun d'entre eux ne devint jamais chancelier du sceau du secret ${ }^{169}$, pas plus que leurs homologues anglais 170 .

Louis IX en 1270 (voir note 20) et il faut attendre 1347 pour que Philippe VI renoue avec cet usage, en nommant parmi ses exécuteurs testamentaires tous ses chambellans, ainsi que le chambellan de France (AN, J 404 ${ }^{\mathrm{B}}, \mathrm{n}^{\mathrm{o}} 33$ ).

166. Sur le rôle de Robert de Lorris, voir en particulier R. Cazelles, Société politique..., p. 77-80.

167. R.-H. Bautier, « Recherches... », p. 74-79 / 688-693.

168. Nous ignorons tout du fonctionnement de cette petite chancellerie sous Philippe VI et du rôle qu'ont pu y jouer les chambellans; le seul individu œuvrant dans ce cadre dont le nom nous soit parvenu - Thierry Valentis, qui effectue les achats de cire pour le petit sceau (R. Fawtier, «Un compte de menues dépenses... », $\left.n^{\circ} 16,37,58 . ..\right)$ - n'a pas laissé d'autre trace dans la documentation.

169. Le titre de «chancelier du sceau du secret » n'exista jamais dans l'administration royale. Toutefois, un document anglais de 1325 mentionne un « gardein (sic) du privé seal ledit roi de France » en la personne du maître des requêtes André de Florence (Pierre Chaplais, The war of Saint-Sardos, 1323-1325: Gascon correspondence and diplomatic documents, Londres, 1954 [Camden third series, 87], $\mathrm{n}^{\circ}$ 167, p. 176). Pierre Jugie, le premier à avoir signalé cette mention, suggère que le scribe de ce document aurait pu commettre deux inexactitudes : d'une part, présenter, sous l'influence du modèle anglais, la garde du sceau du secret confiée aux chambellans comme un office et d'autre part l'attribuer à André de Florence, au lieu du chambellan Hugues de Bouville mentionné avec lui (Pierre Jugie, «Cardinaux et chancelleries pendant la papauté d'Avignon : une voie royale vers les honneurs? », dans Offices et papauté, $X I V^{e}-X V I I^{e}$ siècle : charges, hommes, destins, éd. Armand Jamme et Olivier Poncet, Rome, 2005 [Collection de l'École française de Rome, 334], p. 651739 , à la p. 671, n. 92). On s'accordera à penser que ce document nous fournit une image déformée de la réalité, mais il n'est pas à exclure que se soit formé un embryon de chancellerie du secret dès le milieu du règne de Charles IV et que les chambellans aient alors perdu la garde du sceau du secret au profit des maitres des requêtes - d'autant que ceux-ci avaient accès à ce sceau dès le règne de Philippe $\mathrm{V}$ (voir p. 380).

170. L'importance prise par la chancellerie du sceau privé à compter du XIII ${ }^{\mathrm{e}}$ siècle en Angleterre (voir notamment Thomas Frederick Tout, Chapters in the administrative history of medieval England: the wardrobe, the chamber and the small seals, Manchester, 19201933, 6 vol., t. I, p. 156-157, et t. II, p. 78-81) a conduit les chambellans à être dépossédés de la garde de ce sceau. Si celui-ci semble avoir d'abord été conservé par les chambellans, au début du XIII ${ }^{\mathrm{e}}$ siècle (ibid., t. I, p. 154, où n'est cependant citée aucune source à l'appui), il gagne bientôt d'autres mains : les rares documents qui évoquent le sceau privé au XIII ${ }^{\mathrm{e}}$ siècle le montrent confié au garde de la garde-robe dans les années 1230 (ibid., t. I, p. 217) puis, dans les années 1290, au contrôleur de la garde-robe (ibid., t. II, p. 37-38). Enfin, au cours du règne d'Édouard II, apparaît un officier spécifique chargé de le conserver, le garde du sceau privé (ibid., t. II, p. 285-286, et Henry Churchill Maxwell-Lyte, Historical notes on the use of the great seal of England, Londres, 1926, p. 22) - T. Tout a certes cru que l'office de garde du 
Au demeurant, le fait que le chambrier soit le seul des grands officiers de la couronne de France à ne pas s'intégrer à l'appareil administratif au $\mathrm{XIV}^{\mathrm{e}}$ siècle ${ }^{171}$ ne suggère-t-il pas que le personnel de la Chambre était voué à rester avant tout composé d'officiers domestiques? L'exemple romain incite à le penser ${ }^{172}$, l'exemple anglais à en douter ${ }^{173}$.

Olivier Canteaut.

sceau privé existait dès 1275 , tout en étant détenu par le contrôleur de la garde-robe (Chapters..., t. II, p. 36) ; mais cette affirmation repose sur un document de 1329, daté de 1275 par erreur (H. C. Maxwell-Lyte, Historical notes..., p. 21, n. 8).

171. R. Cazelles, «Un problème d'évolution... », p. 186-187. Toutefois je ne rejoins pas les conclusions de R. Cazelles qui considère que ce sont les chambellans qui, en lieu et place des chambriers, se sont intégrés à la monarchie administrative de la fin du Moyen Âge : aussi longue soit la liste des chambellans qui ont eu quelque influence politique, ceux-ci n'ont pas pour autant acquis une place stable à la tête d'un service administratif.

172. Le personnel de la Chambre n'exerce qu'une influence très réduite dans le gouvernement de l'Église : les chambriers du pape jouissent de la familiarité du souverain pontife et œuvrent parfois à la préparation matérielle des lettres secrètes, mais ils restent des officiers domestiques dépourvus de toute influence au sein de la Curie (voir Bernard Guillemain, $L a$ cour pontificale d'Avignon, 1309-1376 : étude d'une société, Paris, 1962 [Bibliothèque des Écoles françaises d'Athènes et de Rome, 201], p. 373-376). Quant au camérier, son rôle est central dans le gouvernement pontifical (ibid., p. 278-280), mais son office ne trouve nullement son origine dans la Chambre du pape (voir Maurice Michaud, «Chambre apostolique », dans Dictionnaire de droit canonique..., dir. Raoul Naz, t. III, Paris, 1942, col. 388431, aux col. 398-400).

173. En Angleterre la Chambre, tout comme d'autres services de l'Hôtel, a réussi à s'intégrer pleinement aux rouages administratifs et financiers de la monarchie. La wardrobe et la great wardrobe, qui assurent la gestion des finances de l'Hôtel et sont ainsi assimilables pour l'une à la Chambre aux deniers et pour l'autre à l'argenterie (The English government at work, 1327-1336, éd. James F. Willard et William A. Morris, t. I : Central and prerogative administration, Cambridge [Mass.], 1940, p. 77-78), ont été les premières à connaître une telle évolution à la fin du XIII ${ }^{\mathrm{e}}$ siècle, puisqu'elles constituent depuis le règne d'Édouard I ${ }^{\text {er }}$ l'ossature administrative et financière de l'armée royale (Michael Prestwich, War, politics and finance under Edward I, Londres, 1972, p. 151-167). La Chambre, à son tour, devient au fil du XIV ${ }^{\mathrm{e}}$ siècle un outil indispensable pour le souverain anglais : elle offre à ce dernier tout à la fois un personnel dévoué, à même de constituer le noyau d'un parti royal, et un système de financement échappant au contrôle du Parlement et des magnats (voir notamment T. F. Tout, Chapters..., t. III, p. 407-408, et t. II, p. 359-360 ; Gerald Leslie Harriss, King, Parliament and public finance in medieval England to 1369, Oxford, 1975, p. 500502). Et si son influence politique fluctue selon les périodes (pour les règnes d'Édouard III et de Richard II, voir T.F. Tout, Chapters..., t. IV, p. 227-343), elle constitue encore un instrument essentiel de la politique financière du souverain au début du Xvi siècle (David Grummitt, «Henry VII, chamber finance and "the New Monarchy" : some new evidence », dans Historical research, t. 72, 1999, p. 229-243, notamment p. 241-243). En dépit de l'importance ainsi acquise par la Chambre anglaise, les chambellans du roi sont le plus souvent restés cantonnés à un rôle mineur, inférieur à celui d'autres officiers, tels le receveur ou les chevaliers de la Chambre (T. F. Tout, Chapters..., t. IV, p. 254-255 et 341-342). Il est vrai que Hugh le Despenser le jeune, chambellan d'Édouard II de 1318 à 1326, ou encore Simon Burley, Robert de Vere et William Scrope, chambellans de Richard II, ont exercé une forte influence sur leur maître (voir notamment ibid., t. II, p. 357-358 sur le Despenser, et 


\section{ANNEXE}

\section{Les Chambellans du RoI Et les Chambellans de France DE 1285 À 1328.}

\section{Règne de Philippe IV \\ (octobre 1285-novembre 1314)}

1285-1286:

Philippe IV reçoit en héritage de son père trois chambellans :

- Pierre V de Chambly, attesté depuis avril 1269 (a. s.) ${ }^{174}$, principal chambel$\operatorname{lan} 175$;

- Jean Poucin, attesté depuis décembre 1270176 ;

- Pierre I de Machau, attesté depuis septembre $1277{ }^{177 .}$

Sans doute Philippe IV hérite-t-il aussi du chambellan de France Mathieu IV de Montmorency, probablement nommé peu après septembre 1285 et attesté à compter d'octobre $1285^{178}$.

À ces hommes s'ajoutent deux nouveaux chambellans, attestés le 23 janvier $1286^{179}$ :

- Pierre VI de Chambly ${ }^{180}$;

ibid., t. III, p. 404, 406-407, et t. IV, p. 10, sur les chambellans de Richard II), mais les chambellans en tant que tels n'acquerront jamais de rôle politique ou administratif durable auprès du souverain. En témoignent notamment l'impossibilité d'établir une liste précise et continue des chambellans du roi au cours du XIv siècle (ibid., t. VI, p. 45-50) ainsi que le remplacement, récurrent dans la seconde moitié du XIv ${ }^{\mathrm{e}}$ siècle, des chambellans du roi par un chambellan héréditaire, que cette charge ait été honorifique ou effective (ibid., t. IV, p. 337-338 et 340-341).

174. BNF, lat. 5462, p. 307. Il y est qualifié de « camerarius domini regis Francorum »; sur cette confusion, voir note 11 .

175. Sa prééminence est attestée par l'article 51 de l'ordonnance de Vincennes du 23 janvier 1286 (AN, JJ 57, fol. 4v).

176. $\mathrm{AN}, \mathrm{JJ} 30^{\mathrm{A}}, \mathrm{n}^{\circ} 595$. C'est à tort qu'il est qualifié de valet de chambre par É. Lalou (Ordonnances de l'Hôtel..., www.cn-telma.fr/ordonnances/nominum/\#ip369).

177. AN, J 208, Chambly, $\mathrm{n}^{\circ} 2$.

178. André du Chesne, Histoire généalogique de la maison de Montmorency et de Laval..., Paris, 1624, Preuves, p. 127. Mathieu succède à Raoul de Nesle, chambellan de France en mars 1284 (L. Delisle, « Essai de restitution d'un volume des Olim perdu depuis le xvi siècle et jadis connu sous le nom de Livre pelu noir, ou Livre des enquêtes de Nicolas de Chartres », dans Boutaric, t. I, appendice, p. 297-464, au n ${ }^{\circ} 537$, p. 389). Or Raoul devient lui-même connétable de France avant juillet 1286 (AN, K 36, no 4), succédant ainsi à Humbert de Beaujeu, mort dès septembre 1285 (Les comptes [...] de la Chambre aux deniers..., p. 86, $\mathrm{J} 45)$.

179. Ordonnance de Vincennes, art. 52, AN, JJ 57, fol. 4v.

180. C'est par erreur que Pierre VI est donné comme chambellan dès 1277 par J. Depoin (« La maison de Chambly... », p. 134, citant à tort AN, J 208, Chambly, $\mathrm{n}^{\circ}$ 2). 
- Hugues II de Bouville, déjà chambellan de Philippe avant son avènement ${ }^{181}$.

Jean Poucin, quant à lui, n'est plus attesté comme chambellan après le 23 janvier $1286^{182}$.

\section{5-1298:}

Pierre I de Machau meurt entre décembre 1295 et le 22 avril $1298^{183}$. Il n'est manifestement pas remplacé ${ }^{184}$.

\section{4-1306:}

Hugues II de Bouville meurt à la bataille de Courtrai le 18 août 1304, 185. Il est sans doute remplacé par Enguerran de Marigny, attesté à compter du 25 mars $1305^{186}$.

Mathieu IV de Montmorency est attesté pour la dernière fois comme chambellan de France le 25 septembre $1304^{187}$ et meurt probablement le 13 octobre $1305^{188}$. Il est remplacé par Mathieu de Trie, attesté comme chambellan de France en septembre $1306^{189}$.

\section{8-1311 :}

Quatre nouveaux chambellans apparaissent entre 1308 et $1310^{190}$, mais il est malaisé de déterminer précisément la date de leur entrée en fonction ${ }^{191}$ :

181. Il est attesté avec ce titre depuis le 13 mars 1283 (BNF, Baluze 54, fol. 183v).

182. Ordonnance du Bois de Vincennes, art. 53, AN, JJ 57, fol. 4v. Jean est encore vivant en 1291, mais il est alors qualifié par Philippe IV de «chambellan de son père » (BNF, lat. 11003, fol. 111v).

183. AN, J 1034 ${ }^{\mathrm{B}}, \mathrm{n}^{\circ}$ 61, et Philippe IV JT, $\mathrm{n}^{\circ}$ 212. C'est par suite d'une confusion de dates qu'Henri Stein le dit encore vivant en 1297 (H. Stein, «Quelques fonctionnaires... », p. 178, d'après $A N, K 177, n^{\circ} 227$ ).

184. Voir note 193.

185. Voir note 18.

186. AN, J 403, $\mathrm{n}^{\circ}$ 16. Sur la succession d'Hugues II de Bouville, voir note 193.

187. A. du Chesne, Histoire généalogique de la maison de Montmorency..., Preuves, p. 133.

188. Il est probablement mort avant septembre 1306, date à laquelle il a déjà un successeur comme chambellan de France en la personne de Mathieu de Trie (voir note suivante), et il est sans doute encore vivant au début de l'année 1305, puisque Mathieu de Trie est mentionné comme grand maître de l'Hôtel du roi dans un compte allant de la Toussaint 1304 à l'Ascension 1305 (Comptes royaux, 1285-1314..., n $\mathrm{n}^{\circ}$ 5983). La date du 13 octobre nous est quant à elle fournie par le martyrologe de Saint-Martin de Montmorency (A. du Chesne, Histoire généalogique de la maison de Montmorency..., Preuves, p. 133).

189. Philippe IV RTC, $\mathrm{n}^{\circ} 280$.

190. C'est à tort que l'on a pu faire de Pierre XI de Chambly, dit Grismouton, un chambellan du roi en 1308 (Philippe IV RTC, $\mathrm{n}^{\circ}$ 402, à corriger d'après $\mathrm{AN}, \mathrm{JJ}$ 40, $\mathrm{n}^{\circ}$ 60).

191. Un compte «pour les feautés et les hommages », relatif aux droits touchés par les chambellans lors de la réception des hommages féodaux (voir note 29), mentionne de nombreux chambellans de Philippe IV ; à ce titre, il a été fréquemment utilisé pour déterminer la date d'entrée en fonction de certains d'entre eux (Comptes royaux, 1285-1314..., t. II, $\mathrm{n}^{\text {os }} 23844$ à 23891, et t. III, additions et corrections, p. 577). Néanmoins ce compte, dépourvu de toute date, s'avère délicat à manier. R. Fawtier le datait des environs de 1306 (ibid., t. III, p. LXXVII), ce qui en ferait la plus ancienne attestation de Jean de Bouville, d'Hugues III de Bouville et de Pierre VII de Chambly en tant que chambellans. Toutefois, 
- Jean de Bouville, attesté comme chambellan en avril $1308^{192}$, mais peut-être déjà en activité depuis plusieurs années ${ }^{193}$; Jean meurt peu après, entre le 20 mai et le 6 août $1308^{194}$;

- Hugues III de Bouville, en fonction au plus tard le 6 août $1308^{195}$, et qui succède peut-être à son frère Jean;

- Pierre VII de Chambly, nommé au plus tard le 25 mars $1309^{196}$;

- Jean de Machau, chambellan à compter du 15 août 1310 au plus tard ${ }^{197}$.

Ces cinq nominations sont presque concomitantes avec le décès des deux plus anciens chambellans de Philippe IV encore en fonction :

- Pierre VI de Chambly, décédé le 18 janvier 1309198 ;

- Pierre V de Chambly, probablement mort le 12 avril $1311{ }^{199}$. C'est sans doute Enguerran de Marigny qui lui succède comme principal chambellan ${ }^{200}$.

d'après les dossiers de la Gallia Philippica conservés à l'Institut de recherche et d'histoire des textes, ce compte ne doit pas être assigné à une date précise : l'ensemble de ses articles concernerait une période s'étendant du 17 janvier 1308 (date de la mort de l'évêque d'Auxerre, citée à l'article $\mathrm{n}^{\circ}$ 23860, cf. Conrad Eubel, Hierarchia catholica medii et recentioris aevi..., t. I, Ratisbonne, 1898, p. 122) à la mi-septembre 1309 (date de la fin de la régale de Sens, l'hommage du nouvel archevêque étant mentionné à l'article $\mathrm{n}^{\circ} 23863$; Inventaire d'anciens comptes..., $\mathrm{n}^{\circ} 188$ ). Une telle étendue chronologique ne permet plus de préciser la chronologie des chambellans.

192. Philippe IV RTC, $\mathbf{n}^{\circ} 981$.

193. J. Favier considère qu'il remplace Pierre I de Machau dès la fin du XIII ${ }^{\mathrm{e}}$ siècle (Un conseiller..., p. 75 / 586). Dans la mesure où Jean sert encore comme valet à l'Hôtel en 1301 et en 1302 (Les comptes [...] de la Chambre aux deniers..., p. 458, CO VIII, no 46, et p. 599, CO XIII, $n^{\circ} 76$ ), cette hypothèse doit être écartée. On ne peut en revanche exclure que Jean ait succédé à son père Hugues II dès 1304. De fait, dès avril 1306, il occupe une position suffisamment éminente pour pouvoir commander un acte royal (AN, $\mathrm{K} 37, \mathrm{n}^{\circ} 33$ ).

194. BNF, Baluze 54, fol. 205-v et fol. 205v-206.

195. Ibid., fol. $205 \mathrm{v}-206$.

196. Philippe IV RTC, $\mathrm{n}^{\circ} 595$. Il ordonnance des dépenses de l'Hôtel dès le $1^{\text {er }}$ février 1307 (Les comptes [...] de la Chambre aux deniers..., p. 778, CE I, $\mathrm{n}^{\circ} 166$ ).

197. Philippe IV RTC, $\mathrm{n}^{\circ} 1624$. Il ordonnance des dépenses de l'Hôtel depuis le 31 octobre 1308 (Les comptes [...] de la Chambre aux deniers..., p. 835, CE II 417) et commande des actes royaux depuis décembre 1309 (Philippe IV RTC, $\mathrm{n}^{\circ}$ 688).

198. Pierre VI, encore vivant le 13 janvier 1309 (BNF, Picardie 311, nº 80), est décédé le 25 mars 1309 (Philippe IV RTC, $n^{\circ}$ 595) ; le jour de sa mort est indiqué par l'obituaire de l'abbaye du Val-Notre-Dame (Obituaires de la province de Sens..., t. I, p. 627). Sa mort était datée à tort du 18 janvier 1308 par J. Depoin («La maison de Chambly... », p. 134).

199. Pierre V, encore vivant en octobre 1309 (Philippe IV RTC, $\mathrm{n}^{\circ}$ 646), est mort avant le 8 juin 1311 (Philippe IV RTC, $\mathrm{n}^{\circ}$ 1298). Toutefois son petit-fils et héritier, Pierre VII, est toujours qualifié de seigneur de Viarmes en mars 1311, sans doute parce que Pierre V détient encore à cette date la seigneurie familiale de Chambly (Philippe IV RTC, $\mathrm{n}^{\circ} 1598$ ). Le nécrologe du Val-Notre-Dame mentionne un « Petrus Hideus de Chambliaco », mort le 12 avril (Obituaires de la province de Sens..., t. I, p. 628) : il s'agit très probablement de Pierre V.

200. Si Jean Favier considère (à tort) que le titre de principal chambellan n'a pas existé (voir note 10), il n'en reconnaît pas moins une prééminence à Enguerran de Marigny parmi les chambellans à compter de 1308 environ (Un conseiller..., p. 74 / 585-586). Or Marigny n'est pas seulement le plus influent des chambellans : à partir de la mort de Pierre $\mathrm{V}$ de Chambly en 1311, il est aussi le plus ancien des chambellans en fonction. 


\section{Règne de Louis X \\ (novembre 1314-juin 1316)}

Louis X hérite du chambellan de France et de quatre chambellans de son père : par ordre d'ancienneté, Enguerran de Marigny, Hugues III de Bouville, Pierre VII de Chambly et Jean de Machau. Encore chambellan en février $1315^{201}$, Enguerran de Marigny est démis de son office, puis pendu le 30 avril $1315^{202}$.

À ces hommes s'ajoutent onze nouveaux venus entre décembre 1314 et juin $1316^{203}$ :

- Louis de Marigny, chambellan dès le 30 décembre 1314, 204 ;

- Pierre IX de Chambly, chambellan de Louis avant son avènement ${ }^{205}$, attesté comme chambellan du roi à partir de février $1315^{206}$;

- Gilles de Sergines, chambellan de Louis avant son avènement ${ }^{207}$, chambellan du roi au plus tard en mars $1315^{208}$;

- Pierre II de Machau, en activité au plus tard en juin $1315^{209}$;

- Hugues d'Augeron, chambellan de Louis avant son avènement ${ }^{210}$, attesté comme chambellan du roi à partir du 17 septembre $1315^{211}$;

- Guillaume Paumier, chambellan de Louis avant son avènement ${ }^{212}$, chambellan du roi au plus tard au second semestre de $1315^{213}$;

- Jean de Chepoix, en activité au second semestre de $1315^{214}$;

- Philippe de Saint-Martin, en activité au second semestre de $1315^{215}$;

- Adam Héron, attesté comme chambellan en juin $1316^{216}$;

- Jean Langre, attesté comme chambellan en juin $1316^{217}$;

- Eudes de Vaussemain, attesté comme chambellan en juin $1316^{218}$.

Nous ignorons qui, parmi eux, était principal chambellan ${ }^{219}$.

201. Louis X RTC, $\mathrm{n}^{\circ} 38$.

202. La chronique métrique..., p. 226-227, v. 7195-7288.

203. Michel de Bourdenay est indiqué à tort comme chambellan de Louis X par É. Lalou («Enguerran de Marigny... », p. 273).

204. Philippe IV JT, $\mathrm{n}^{\circ} 6081$.

205. Voir note 107.

206. Louis XRTC, $\mathrm{n}^{\text {os }} 37$ et 44.

207. Voir note 107 .

208. Louis X RTC, $\mathrm{n}^{\circ} 58$.

209. Ibid., $\mathrm{n}^{\circ} 164$.

210. Voir note 107.

211. BNF, Clairambault $8, \mathrm{n}^{\circ} 14$.

212. Voir note 107.

213. BNF, fr. 7855, p. 138.

214. Ibid.

215. Ibid.

216. AN, J $404^{\mathrm{A}}, \mathrm{n}^{\mathrm{o}} 22$.

217. Ibid.

218. Ibid.

219. Le compte de l'Hôtel du second semestre de 1315 mentionne Pierre VII de Chambly en tête de liste, mais celui-ci touche les mêmes gages que les autres (BNF, fr. 7855, p. 138). En juin 1316, le testament de Louis $X$ prévoit un legs plus élevé pour Hugues d'Augeron, mais la hiérarchie complexe qu'il instaure entre les chambellans reflète sans 
Tous, à l'exception de Louis de Marigny, démis après le second semestre de $1315^{220}$, sont encore en exercice en juin $1316^{221}$.

\section{Régence de Philippe de Poitiers et règne de Philippe V (juillet 1316-janvier 1322)}

À la fin du mois de juillet 1316, Philippe de Poitiers nomme trois chambellans 222 qu'il conservera durant tout son règne :

- Adam Héron, principal chambellan, ancien chambellan de Philippe et de Louis $\mathrm{X}^{223}$, attesté jusqu'au dernier semestre de $1321^{224}$;

- Robert (ou Robillard) de Gamaches, ancien chambellan de Philippe ${ }^{225}$, et encore chambellan du roi en décembre $1321^{226}$;

- Gui de Séry, dit le Borgne de Séry, actif jusqu'au dernier semestre de $1321{ }^{227}$.

Mathieu de Trie demeure chambellan de France jusqu'à la fin de l'année $1317^{228}$. Son successeur, Jean de Melun, n'est attesté qu'à compter d'août $1320{ }^{229}$.

doute les liens qui unissent le roi à chacun d'eux plutôt que leur place respective au sein de la Chambre (AN, J 404, ${ }^{\mathrm{A}} \mathrm{n}^{\mathrm{o}} 22$ ).

220. Il touche encore des gages comme chambellan d'après le compte de l'Hôtel de cette période (BNF, fr. 7855, p. 138).

221. AN, J $404^{\mathrm{A}}, \mathrm{n}^{\mathrm{o}} 22$.

222. Ordonnance de Saint-Germain, art. 10, AN, JJ 57, fol. 42. Sur la date précise de cette ordonnance, voir O. Canteaut, Gouvernement..., t. III, p. 709.

223. Voir note 114 .

224. BNF, fr. 9499, p. 50 (compte de l'Hôtel de la reine du $1^{\text {er }}$ juillet 1321 au 6 janvier 1322).

225. AN, JJ 57, fol. 25.

226. Philippe V RTC, $\mathrm{n}^{\circ}$ 3591. Il est également mentionné dans un compte de l'Hôtel de la reine pour la période du $1^{\text {er }}$ juillet 1321 au 6 janvier 1322 (BNF, fr. 9499, p. 50).

227. BNF, fr. 9499 , p. 50.

228. Philippe V RTC, $\mathbf{n}^{\circ} 1518$; cette liste semble avoir été établie pour l'envoi de mandements expédiés le 13 octobre et le 15 novembre 1317 (Philippe V RTC, ${ }^{\text {os }} 1522$ et 1523 , et $\mathrm{n}^{\text {os }} 1519,1520,1525$ et 1526). Mathieu est encore qualifié de chambellan dans un acte royal de janvier 1323 (Charles IV RTC, $\mathrm{n}^{\circ}$ 4058), mais cette indication, unique, semble bien être due à une erreur de rédaction de la charte royale : le notaire, après y avoir vidimé des actes où Mathieu était chambellan de France, puis après y avoir rappelé les services antérieurs de Mathieu, se sera sans doute laissé emporter jusqu'à faire de lui un chambellan de Charles IV.

229. Philippe V RTC, $n^{\circ} 3239$. Il n'est alors qualifié que de «chambellan », mais sa qualité de chambellan de France est confirmée par un acte de 1321 (Souverains et princes... [cité note 137], $\mathrm{n}^{\circ}$ 5). Par ailleurs, un acte du 7 juillet 1319 en faveur de Jean a été commandé «per regem presente cambellan[o ...]» (BNF, Clairambault 177, $\mathrm{n}^{\circ} 57$ ); la fin de cette mention hors teneur a malheureusement disparu, mais il est possible qu'elle désigne Jean, qui exercerait dès cette date la fonction de chambellan de France. Quant au P. Anselme, il affirme que Jean est chambellan de France dès la campagne de Flandre de 1318 (Histoire généalogique..., t. VIII, p. 443-444); néanmoins, aucun des documents qui mentionnent la participation de Jean à l'ost (voir note 133) ne lui attribue ce titre. 


\section{Règne de Charles IV \\ (janvier 1322-janvier 1328)}

Charles IV renouvelle à son avènement l'ensemble des chambellans royaux, à l'exception du chambellan de France, et nomme en janvier 1322 trois nouveaux chambellans 230 :

- Anseau de Chantemelle;

- Gui de Ribécourt;

- Gui de La Roche.

Dès le premier semestre de 1322, s'y ajoutent deux chambellans supplémentaires $^{231}$ :

- Hugues III de Bouville ${ }^{232}$;

- Gui de Séry qu'on retrouve, après une probable interruption, aux fonctions qu'il occupait à la fin du règne de Philippe $\mathrm{V}$.

Nous ignorons qui, parmi eux, était principal chambellan ${ }^{233}$.

Tous sont encore en activité au premier semestre de $1327^{234}$ et l'étaient probablement encore à la mort de Charles IV en janvier $1328{ }^{235}$.

Aucun des cinq chambellans du roi ne semble servir encore Philippe VI à son avènement ${ }^{236}$. En revanche, le chambellan de France, Jean de Melun, conservera son office jusqu'à sa mort, entre 1351 et 1352237.

230. Ordonnance de janvier 1322, art. 3, BNF, fr. 7855, p. 265.

231. BNF, fr. 7855 , p. 289.

232. Il est également attesté avec le titre de chambellan le $1^{\text {er }}$ juin 1322 (BNF, Baluze 54, fol. $212 \mathrm{v})$.

233. Tous perçoivent les mêmes gages au premier semestre de 1322 (BNF, fr. 7855, p. 289). Remarquons cependant que Gui de Ribécourt est toujours nommé en tête des trois listes de chambellans que nous possédons pour le règne de Charles IV (ibid., p. 265 et 289; Comptes royaux, 1314-1328..., $\mathrm{n}^{\circ} 14307$ ).

234. Ibid.

235. Gui de La Roche est encore attesté comme chambellan à cette date (Charles IV RTC, $\mathrm{n}^{\circ}$ 5338).

236. Nous ne possédons aucune liste des chambellans de Philippe VI avant celle de 13311332 (J. Viard, «L'Hôtel de Philippe VI... », p. 604) ; on ne peut donc exclure que certains chambellans de Charles IV aient conservé quelque temps leur charge à l'avènement de Philippe VI, même si aucun document ne l'atteste. Ainsi Gui de Séry est-il peut-être encore chambellan du roi lorsqu'il se voit confier le heaume de Philippe VI à la bataille de Cassel, en août 1328 (voir note 18).

237. Le P. Anselme situe son décès en 1350, avant la mort de Philippe VI (Histoire généalogique..., t. V, p. 225); R. Cazelles affirme en revanche qu'il ne meurt qu'au début du règne de Jean II (Société politique..., p. 72). C'est que la date de décès de Jean est difficile à déterminer dans la mesure où son fils, lui aussi prénommé Jean, lui a succédé comme chambellan de France (voir notamment AN, JJ 81, nº 185, et le P. Anselme, Histoire généalogique..., t. VIII, p. 444). De fait, nous ne disposons que des titres de seigneur de Tancarville et de chambellan de Normandie, que Jean II a hérités de sa mère (le P. Anselme, Histoire généalogique..., t. V, p. 225), pour distinguer Jean I de son fils. Seules certitudes : Jean I est décédé en août $1352\left(\mathrm{AN}, \mathrm{JJ}\right.$ 81, $\mathrm{n}^{\circ}$ 360), voire très probablement dès le 4 février 1352 (AN, JJ 81, $\mathrm{n}^{\circ} 185$, qui qualifie le chambellan de Normandie [Jean II] de vicomte de Melun), mais il était sans doute encore vivant en mars 1351, date à laquelle son fils n'est encore qualifié que de « chambellan de Tancarville » (AN, JJ 80, nº 327). 